$\begin{array}{llll}\text { Journal: } & \text { GCA } & \text { revised version } & \text { November } 2014\end{array}$

\title{
Reduced partition function ratios of iron and oxygen in goethite
}

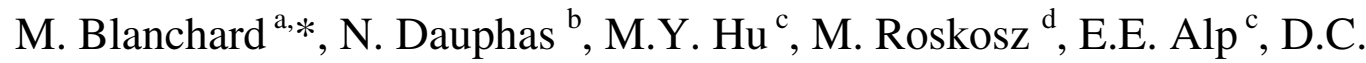 \\ Golden $^{\text {e }}$, C.K. Sio ${ }^{\text {b }}$, F.L.H. Tissot ${ }^{\text {b }}$, J. Zhao ${ }^{\text {c }}$, L. Gao ${ }^{\text {c }}$, R.V. Morris ${ }^{\mathrm{e}}$, M. \\ Fornace $^{\mathrm{b}}$, A. Floris ${ }^{\mathrm{g}}$, M. Lazzeri ${ }^{\mathrm{a}}$, E. Balan ${ }^{\mathrm{a}}$
}

${ }^{a}$ Institut de Minéralogie, de Physique des Matériaux, et de Cosmochimie (IMPMC), Sorbonne Universités - UPMC Univ Paris 06, UMR CNRS 7590, Muséum National d'Histoire Naturelle, IRD UMR 206, 4 Place Jussieu, F-75005 Paris, France.

b Origins Laboratory, Department of the Geophysical Sciences and Enrico Fermi Institute, The University of Chicago, 5734 South Ellis Avenue, Chicago, IL 60637, USA

${ }^{\mathrm{c}}$ Advanced Photon Source, Argonne National Laboratory, 9700 South Cass Avenue, Argonne, IL 60439, USA

${ }^{\mathrm{d}}$ Unité Matériaux et Transformations, Université Lille 1, CNRS UMR 8207, 59655

Villeneuve d'Ascq, France

${ }^{\mathrm{e}}$ Engineering and Science Contract Group-Hamilton Sundstrand, Mail Code JE23, Houston, TX 77058, USA

${ }^{\mathrm{f}}$ NASA Johnson Space Center, Houston, TX, USA

${ }^{g}$ Department of Physics, King's College London, London, Strand WC2R 2LS, United Kingdom

Corresponding Author: Marc Blanchard ( marc.blanchard@impmc.upmc.fr )

Tel.: +33144279822～Fax: +33144273785 


\begin{abstract}
First-principles calculations based on the density functional theory (DFT) with or without the addition of a Hubbard $U$ correction, are performed on goethite in order to determine the iron and oxygen reduced partition function ratios ( $\beta$ factors). The calculated iron phonon density of states (pDOS), force constant and $\beta$ factor are compared with reevaluated experimental $\beta$ factors obtained from Nuclear Resonant Inelastic X-ray Scattering (NRIXS) measurements. The reappraisal of old experimental data is motivated by the erroneous previous interpretation of the lowand high-energy ends of the NRIXS spectrum of goethite and jarosite samples (Dauphas et al. 2012). Here the NRIXS data are analyzed using the SciPhon software that corrects for non-constant baseline. New NRIXS measurements also demonstrate the reproducibility of the results. Unlike for hematite and pyrite, a significant discrepancy remains between DFT, NRIXS and the existing Mössbauer-derived data. Calculations suggest a slight overestimation of the NRIXS signal possibly related to the baseline definition. The intrinsic features of the samples studied by NRIXS and Mössbauer spectroscopy may also contribute to the discrepancy (e.g. internal structural and/or chemical defects, microstructure, surface contribution). As for oxygen, DFT results indicate that goethite and hematite have similar $\beta$ factors, which suggests almost no fractionation between the two minerals at equilibrium.
\end{abstract}




\section{INTRODUCTION}

For decades now, the isotopic compositions of natural samples have been measured and found countless applications in all branches of geosciences (see for reviews, Valley and Cole, 2001; Johnson et al. 2004; Eiler et al. 2014). In the meantime, isotope exchange experiments were performed to improve our understanding of the processes responsible for stable isotope fractionation. More recently, new approaches have emerged and are contributing to this field of research First-principles calculations give reduced partition function ratios (also called $\beta$ factors) that can be combined for two phases in order to obtain the equilibrium isotope fractionation factor (ofactor), which is the quantity usually measured. These theoretical methods are also of great interest for investigating the mechanisms controlling the isotope fractionation at the molecular scale. For Mössbauer active elements (like iron), $\beta$ factors can also be obtained using Mössbauer spectroscopy through the measurement of the temperature dependence of the isomer shift (Polyakov and Mineev, 2000) or using Nuclear Resonant Inelastic X-ray Scattering (NRIXS, Polyakov et al., 2005, 2007; Dauphas et al., 2012, 2014).

Dauphas et al. (2012) and Hu et al. (2013) reported NRIXS data for ${ }^{57} \mathrm{Fe}-$ rich goethite $\mathrm{FeO}(\mathrm{OH})$, hydronium-jarosite $\left(\mathrm{H}_{3} \mathrm{O}\right) \mathrm{Fe}_{3}\left(\mathrm{SO}_{4}\right)_{2}(\mathrm{OH})_{6}$ and potassium jarosite $\mathrm{KFe}_{3}\left(\mathrm{SO}_{4}\right)_{2}(\mathrm{OH})_{6}$. From such measurements, one can deduce iron $\beta$ factors as a function of temperature. Polyakov et al. (2007) had used projected partial phonon density of states (pDOS) obtained using this technique to calculate $\beta$ factors for various phases. Dauphas et al. (2012) and Hu et al. (2013) used a different approach based on moment estimates of NRIXS scattering spectrum $\mathrm{S}(\mathrm{E})$, which simplifies

evaluation of measurement uncertainties and potential systematic errors. The study of Dauphas et al. (2012) was the first of its kind in measuring NRIXS spectra 
specifically for applications to isotope geochemistry. In doing so, they encountered a difficulty that had been unappreciated before concerning the baseline at low and high energies. Most previous studies in geosciences had focused on estimating the Debye sound velocity (Hu et al. 2003; Sturhahn and Jackson, 2007), from which compressional and shear wave velocities can be deduced if the bulk modulus and density of the phase are known. These estimates are derived from parts of the spectra that are close to the elastic peak for the nuclear transition of ${ }^{57} \mathrm{Fe}$ at $14.4125 \mathrm{keV}$. On the other hand, the force constant, which controls $\beta$ factors, is heavily influenced by details of the spectrum at the low- and high-energy ends of the spectrum. As a result, little attention had been paid to the accuracy of force constant measurements by NRIXS. Dauphas et al. (2012) found that in some cases, significant counts were present even at high energies. The projected partial phonon density of states, $g(E)$, and the scattering spectrum, $\mathrm{S}(\mathrm{E})$, never reached zero and as a result, the integrals that gave the force constants did not plateau for goethite and $\mathrm{H}$-jarosite. These were interpreted to reflect the presence of multiple phonons at high energies. However, we were unable to replicate the measurements during another session of NRIXS measurements at the Advanced Photon Source synchrotron. This and other tests performed on other phases convinced us that the high counts in the tails are not from multiple phonons but rather reflect the presence of a non-constant baseline. To address this issue, Dauphas and collaborators have developed a software (SciPhon) that reliably corrects for non-constant baseline (Dauphas et al, 2014).

In the present study, the pDOS as well as the iron and oxygen $\beta$ factors of goethite are computed using first-principles calculations and compared to available experimental isotopic data. In parallel, the data published in Dauphas et al. (2012) have been re-evaluated using SciPhon and we present revised estimates for the force 
constants of goethite and jarosite. To validate the approach and evaluate the long-term reproducibility of force constant measurements by NRIXS, we have analyzed the goethite sample two more times and the jarosite samples one more time. Those new results, together with a re-evaluation of previous data, are reported here.

\section{MATERIALS AND METHODS}

\subsection{NRIXS spectroscopy}

Nuclear resonant inelastic X-ray scattering is a nuclear spectroscopic technique that uses the nuclear transition of ${ }^{57} \mathrm{Fe}$ at $14.4125 \mathrm{keV}$ to probe the vibration properties of iron (Seto et al. 1995; Sturhahn et al. 1995). The method as implemented at sector 3-ID-B of the Advanced Photon Source at Argonne National Laboratory is briefly described hereafter. The incident beam is a pulsed X-ray beam of $70 \mathrm{ps}$ duration and $153 \mathrm{~ns}$ interpulse duration. A monochromator restricts the energy spread of the incident beam to $1 \mathrm{meV}$. When the pulse hits the sample, X-rays are scattered by electrons and this electronic contribution is almost instantaneous. On the other hand, the excited ${ }^{57} \mathrm{Fe}$ nuclei have a finite lifetime of $141 \mathrm{~ns}$ and the electronic contribution can be eliminated from the signal by applying some time discrimination. The signal from NRIXS is measured using Avalanche Photodiodes (APD). The energy is scanned around the nominal resonant energy over a typical interval of -150 to $+150 \mathrm{meV}$. When the photon energy is higher than the resonance energy, the excess energy can be lost to excitation of phonon modes in the lattice and the nuclear excitation can still occur (phonon creation). When the energy is lower than the nominal resonance energy, the energy deficit can be provided by lattice vibrations and the nuclear excitation can still occur (phonon annihilation). 
From NRIXS spectra one can calculate $\beta$ factors by taking the moments of the scattering spectrum S(E) (Dauphas et al. 2012; Hu et al. 2013) or the projected partial phonon density of states $\mathrm{g}(\mathrm{E})$ (Polyakov et al. 2005, Dauphas et al. 2012). In the present study, all samples were fine powders (isotropic) and the calculated pDOS represents an average from contributions of all crystallographic orientations. The pDOS is partial in the sense that NRIXS is only sensitive to ${ }^{57} \mathrm{Fe}$. Using $\mathrm{S}(\mathrm{E})$, the formula that gives $\beta$ factors is (Dauphas et al. 2012),

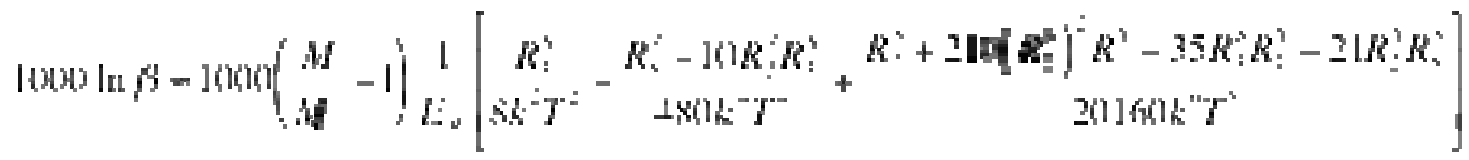

, (Eq. 1)

where $M$ and $M^{*}$ are the masses of the two isotopes considered (e.g., 56 and 54), $E_{R}$ is the free recoil energy ( $1.956 \mathrm{meV}$ for $\left.{ }^{57} \mathrm{Fe}\right), k$ is Boltzmann's constant, $T$ is the temperature, and $R_{i}^{S}$ is the $i^{\text {th }}$ centered moment of $\mathrm{S}$ given by

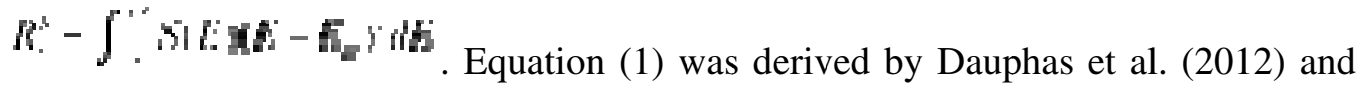
Hu et al. (2013) using two different mathematical approaches (expansions in powers of temperature $v s$. thermalized moments).

The $k$-factors can also be calculated from $\mathrm{g}(\mathrm{E})$ using the formula that is valid for $E / k T$ $<2 \pi$ (Polyakov et al. 2005, Dauphas et al. 2012),

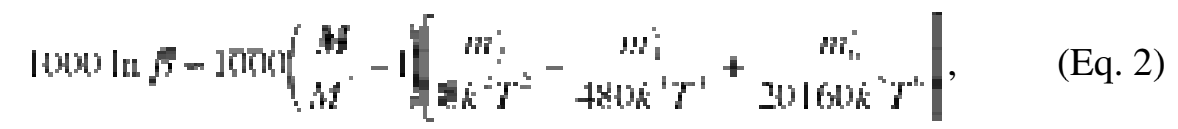

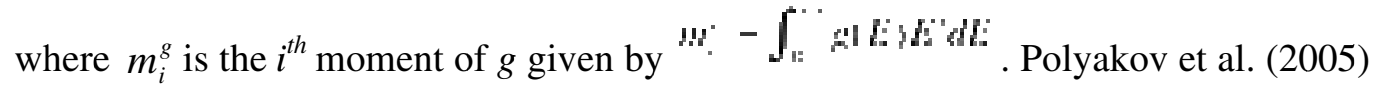
obtained this formula using perturbation theory and an expression of the kinetic energy while Dauphas et al. (2012) obtained this formula using a Bernoulli expansion of the reduced partition function ratio. In general, $\beta$ factors can be expressed as, 


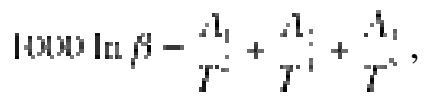

where the coefficients $A_{1}, A_{2}$, and $A_{3}$ can be calculated from either Eq. 1 (S) or Eq. 2 (g). The pDOS $g$ is calculated from $S$ using a Fourier-Log decomposition (Johnson and Spence, 1974; Sturhahn et al. 1995; Sturhahn 2000; Kohn and Chumakov 2000) and Eqs. 1 and 2 are mathematically equivalent. In practice, Eq. 1 is easier to use as errors are not correlated between different energy channels and it is more straightforward to assess the effects of the data reduction procedure (e.g., truncation in energy, baseline subtraction) on the estimates of the $\beta$ factor coefficients. The above-mentioned equations can also be written as (Dauphas et al. 2012),

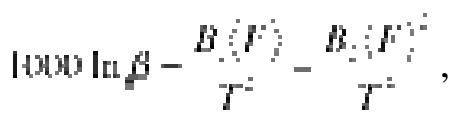

where $B_{1} \quad, B_{2}$ is a constant that depends on the shape of the pDOS and $\langle F\rangle$ is the mean force constant (in $\mathrm{N} / \mathrm{m}$ ) of the bonds holding iron in position,

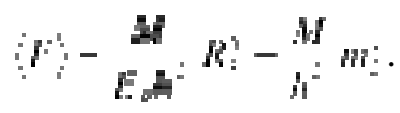

The same samples as those initially measured by Dauphas et al. (2012) were used in this study and details on the synthesis method can be found in Golden et al. (2008). All samples were made starting with ${ }^{57} \mathrm{Fe}$-rich metal $(95 \%$ vs $2.1 \%$ natural abundance) as NRIXS is only sensitive to this Mössbauer isotope. The nature of the minerals analyzed was checked by X-ray powder diffraction (XRD). The Rietveld refinement (JADE software package, Materials Data Inc.) provided the following unit-cell parameters for the goethite sample: $a=4.58 \AA, b=9.94 \AA, c=3.02 \AA$ (Pbnm space group). The particle sizes (equivalent sphere diameters of coherent domain sizes) were determined using the peak broadening of Rietveld-refined XRD, yielding $19.8 \mathrm{~nm}$ for goethite and $223.0 \mathrm{~nm}$ for K-Jarosite. Goethite particles are 
usually acicular. In Dauphas et al 2012, the powdered samples were mounted in compressed pellets, which could impart preferential orientation of the samples, as rightly noticed by Frierdich et al. (2014). However, the latter measurements were done on the powdered samples mounted in vacuum grease at the tip of a kapton capillary, which should keep a random orientation of the particles. One or two APDs were mounted on the sides of the sample perpendicular to the incident beam, so as to capture the maximum solid angle of scattered X-rays. The forward signal was measured at the same time, providing an accurate estimate of the resolution function.

The data reduction was entirely done using a new software called SciPhon that is introduced briefly in Dauphas et al. (2014) and will be the scope of a forthcoming publication. The main difference with the data reduction protocol used by Dauphas et al. (2012) is the recognition that signal is present at the low and high energy ends of the spectrum at a level that is too high to be explained by the presence of multiple phonons. The approach used in SciPhon is to remove a linear baseline that is calculated by interpolating the data between the low and high-energy ends of the spectrum and truncating the data when the signal reaches a constant value. This is an effective method when a broad enough energy scan is acquired and one can clearly make the cut between what is signal and what is baseline. After truncation and baseline subtraction, the missing signal is reconstructed by calculating the contribution from the missing multiple phonons using a first estimate of $g$ obtained from truncated $S$. When the baseline at the high-energy end is higher than at the lowenergy end (most common situation), the correction for non-constant baseline brings the force constant down. Conversely, when the baseline at the high-energy end is lower than at the high-energy end, the correction brings the force constant up. The other features of SciPhon are deconvolution of the resolution function using a steepest 
descent algorithm, removal of the elastic peak using a refined interpolation method, calculation of all parameters needed for application of NRIXS data to isotope geochemistry (Eqs. 1 and 2), and propagation of all uncertainties (not only counting statistics but also errors on baseline subtraction and energy scaling) on parameters derived from $\mathrm{S}$. We applied the same algorithm to the new data reported here and to the raw data reported in Dauphas et al. (2012).

\subsection{Computational methods}

Goethite $(\alpha \mathrm{FeOOH})$ has an orthorhombic unit cell $(\mathrm{a}=4.598 \AA$, b $=9.951 \AA$, c = $3.018 \AA$, Pbnm space group, Yang et al. 2006), containing four formula units. Calculations are done with the PWscf code (Giannozzi et al., 2009; http://www.quantum-espresso.org) using the density functional theory (DFT) and the generalized gradient approximation (GGA) to the exchange-correlation functional with the PBE parameterization (Perdew et al. 1996). The ionic cores are described by the ultrasoft pseudopotentials Fe.pbe-nd-rrkjus.UPF, O.pbe-rrkjus.UPF, H.pberrkjus.UPF, as in Blanchard et al. (2009, 2010, 2014). The wave-functions and the charge density are expanded in plane-waves with 40 and 480 Ry cutoffs, respectively. Increasing these energy cutoffs to 60 and 720 Ry does not modify significantly the vibrational frequencies $(<1 \%)$. For the electronic integration, the Brillouin zone is sampled according to the Monkhorst-Pack scheme (Monkhorst and Pack 1976), using shifted $4 \times 2 \times 6 k$-point grids. Increasing the number of $k$-points does not modify the structural and vibrational properties. Calculations are spin-polarized and set up to the antiferromagnetic structure. The spins are oriented along the $c$-axis of goethite with up and down spins in alternate chains of octahedra (Cornell and Schwertmann, 2003). Magnetic moments are free to relax. Atomic positions are relaxed until the residual 
forces on atoms are less than $10^{-4}$ Ry/a.u..

Additional calculations were performed using the GGA $+U$ method since it is known that the addition of a Hubbard $U$ correction on the $\mathrm{Fe}$ atom improves the description of the electronic and elastic properties of goethite by taking into account the strong on-site Coulomb repulsion of Fe $3 d$ electrons (e.g. Otte et al. 2009). The value of the Hubbard $U$ is determined using a linear response approach in an internally consistent way following the procedure proposed by Cococcioni and de Gironcoli (2005) and Kulik et al. (2006). Details about the practical procedure can be found in Blanchard et al. (2008). The value of the Hubbard $U$ is found equal to 3.34 $\mathrm{eV}$, a value similar to the $3.30 \mathrm{eV}$ found for hematite (Blanchard et al. 2008).

Following the method described in Blanchard et al. (2009), the $\beta$ factors were calculated from the harmonic vibrational frequencies using

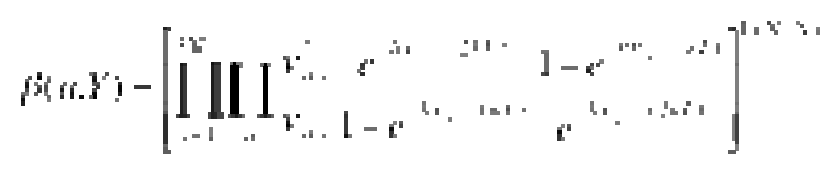

where $v_{q, i}$ are the frequencies of the phonon with wavevector $q$ and branch index $\mathrm{i}=$ $1,3 N_{a t} \cdot N_{a t}$ is the number of atoms in the unit cell, while $v_{q, i}$ and $v_{q, i}$ are the vibrational frequencies in two isotopologues. $N$ is the number of sites for the $Y$ atom in the unit cell, $T$ is the temperature, $h$ is the Planck constant and $k$ is the Boltzmann constant. Phonon frequencies were calculated within the harmonic approximation using the linear response theory (Baroni et al. 2001, Floris et al. 2011) as implemented in the PHonon code (Giannozzi et al., 2009; http://www.quantum-espresso.org). Phonon frequencies were computed on shifted $2 \times 2 \times 2 q$-point grids, for which the convergence of the $f$-factors is achieved. 
The $\beta$ factors calculated from the pDOS (Eq. 2) are identical to the $\beta$ factors calculated directly from the harmonic vibrational frequencies (Eq. 6) providing that the highest energy of the pDOS is smaller than $2 \pi k T$. When it is not the case (i.e. when $\mathrm{OH}$ stretching modes are considered in the pDOS) the formula derived from perturbation theory (Eq. 1-4 in Polyakov et al. 2005) must be used instead.

\section{RESULTS}

\subsection{Reappraisal of NRIXS data}

The two motivations for implementing a non-constant baseline subtraction procedure were that (1) replicate measurements of a given phase over several years yielded force constant values that were not reproducible and (2) the signal at the low and high energy ends of the spectrum often did not reach zero, so that the force constant integral did not converge. In Fig. 1, we show force constant determinations with or without baseline subtraction for goethite and jarosite. The values without baseline subtraction were processed in the same manner as in Dauphas et al. (2012), meaning that a constant background was subtracted, which is given by the average counts measured in a $10 \mathrm{meV}$ window at the low-energy end of the spectrum (e.g., from -130 to $-120 \mathrm{meV}$ ). The values without baseline subtraction differ slightly from those reported by Dauphas et al. (2012) and Hu et al. (2013) because we now only use the phonon-creation side to calculate the force constant (the phonon-annihilation side is calculated from the detailed balance and the temperature). The phonon annihilation side is still measured to define the low-energy end of the baseline but this side of the spectrum often suffers from low counting statistics, which is the reason why it is not used to calculate the mean force constant. When no baseline is subtracted, the force constant values show variations from one sample to another that far exceed individual 
error bars (reduced $\chi^{2}=13.2$ ). When the data are corrected for the presence of a nonconstant baseline, the average force constant does not change but the sample-tosample scatter is very much reduced (reduced $\chi^{2}=3.1$ ). The improvement in reproducibility (Fig. 1) and better consistency with force constant estimates from theory (see Sect. 3.2.1) justify our preference of the non-constant baseline data reduction algorithm (Dauphas et al., 2014). Below, we discuss the results for each phase individually.

\subsubsection{Goethite}

Including the measurements published by Dauphas et al. (2012), goethite was analyzed by NRIXS three times. As explained in Dauphas et al. (2014) and the method section, the main difference in the data reduction approach used here versus that used by Dauphas et al. (2012) is the recognition that the non-zero signals at the low- and high-energy ends of the spectrum are not from multiple phonons but rather some non-constant baseline. Dauphas et al. (2012) used the counts at the low energy end as baseline and interpreted the non-zero counts at the high-energy end to reflect the presence of multiple phonons. Because the signal never reached zero for goethite, a correction for missing multiple phonons was even applied, which exacerbated the problem. The new approach removes a linear baseline interpolated between the lowand high-energy ends of the spectrum using the SciPhon software (Dauphas et al. 2014). Various quantities calculated from $S(E)$ and $g(E)$ are compiled in Table 1. The pDOS calculated for the three goethite samples are very reproducible and the average pDOS is plotted in Fig. 2.

As shown in Table 1 and later in Table 5 for jarosite samples, $B_{2}$ (Eq. 4 ) is almost the same for the phases investigated $(\sim 59,000)$, so the force constant is the 
main controlling factor in iron isotopic fractionation even at low temperature and we will focus on the values of the force constants in comparing the results obtained by Dauphas et al. (2012) and Hu et al. (2013) with those presented here. The force constant values obtained from $g$ are identical to those obtained from $S$, so we will only discuss the values obtained from $S$ in the following.

For goethite, Dauphas et al. (2012) reported force constants of $307 \pm 9 \mathrm{~N} / \mathrm{m}$ from $S$ and $314 \pm 10 \mathrm{~N} / \mathrm{m}$ from $S$ after refinement. Hu et al. (2013) obtained similar values using the same data reduction approach. Significant signal remained at the high-energy end and as a result the force constant integral did not plateau (Fig. 6 of Dauphas et al., 2012), the new truncation-linear baseline subtraction protocol applied to the same data (using SciPhon) leads to a significant reduction of the force constant, i.e. $277 \pm 15 \mathrm{~N} / \mathrm{m}$. The larger error bar reflects the fact that additional sources of uncertainties associated with baseline subtraction and energy scaling are propagated in the calculation of the force constant (Hu et al. 2013, Dauphas et al. 2014). The two new goethite measurements yield force constants of $264 \pm 13 \mathrm{~N} / \mathrm{m}$ and $267 \pm 13 \mathrm{~N} / \mathrm{m}$, averaging to $268 \pm 8 \mathrm{~N} / \mathrm{m}$ for the three goethite measurements.

\subsubsection{Jarosite}

Including the measurements published by Dauphas et al (2012), hydronium (H-) jarosite and potassium (K-) jarosite were analyzed twice each. Like for goethite, various quantities calculated from $S(\mathrm{E})$ and $g(\mathrm{E})$, using the new data reduction algorithm, are compiled in Table 2. The pDOS calculated for the two H-jarosite, and two K-jarosite samples are very reproducible and the average pDOS are plotted in Fig. 3. 
The force constant for H-jarosite reported by Dauphas et al. (2012) was 302 \pm 9 $\mathrm{N} / \mathrm{m}$ from $S$ and $310 \pm 9$ from $S$ after refinement. Data reduction using SciPhon yields a force constant for this sample of $273 \pm 15 \mathrm{~N} / \mathrm{m}$. A second measurement of this sample during a different session gives $289 \pm 17 \mathrm{~N} / \mathrm{m}$. The average force constant for the two $\mathrm{H}$-jarosite measurements is $280 \pm 11 \mathrm{~N} / \mathrm{m}$.

The force constant of K-jarosite reported by Dauphas et al. (2012) was $262 \pm 6$ $\mathrm{N} / \mathrm{m}$ from $S$ and $264 \pm 6$ from $S$ after refinement. The revised estimate using SciPhon gives a force constant of $279 \pm 16 \mathrm{~N} / \mathrm{m}$. A second force constant measurement of this sample during another session gives a force constant of $305 \pm 18 \mathrm{~N} / \mathrm{m}$. The average of these two values is $290 \pm 12 \mathrm{~N} / \mathrm{m}$.

In the case of $\mathrm{H}$-jarosite, for which significant signal remained at the highenergy end and as a result the force constant integral did not converge (Fig. 6 of Dauphas et al., 2012), the new data-reduction leads to a significant reduction of the force constant. In the case of K-jarosite, the force constant integral plateaued and the estimated force constant does not change significantly with the new data reduction scheme used in SciPhon. Note that Dauphas et al. (2012) had no satisfactory explanation as to why the force constant of $\mathrm{H}$-jarosite was significantly higher than $\mathrm{K}$ jarosite, other than invoking the presence of high-energy modes arising from hydrogen vibrations. The results presented here show that the force constants of Hjarosite and K-jarosite are indistinguishable (280 $\pm 11 \mathrm{~N} / \mathrm{m}$ vs. $290 \pm 12 \mathrm{~N} / \mathrm{m})$.

\subsection{First-principles determination of isotopic fractionation properties}

\subsubsection{Iron $\beta$ factor of goethite}

In first-principles calculations, the goethite cell parameters were fixed to their experimental values (Yang et al., 2006) and atomic positions were relaxed using 
either GGA or GGA $+U$ methods. GGA atomic positions are in excellent agreement with the experimental values (Table 3). Only the $\mathrm{x}$ atomic coordinate of $\mathrm{H}$ atoms shows a significant discrepancy revealing the difficulty of DFT to treat hydrogen bonds as well as the difficulty to determine experimentally the $\mathrm{H}$ positions. The $\mathrm{GGA}+U$ performs similarly as GGA for the description of interatomic distances (Table 4). This is also true for the vibrational properties. We observe a good correlation between experimental and theoretical frequencies for both GGA and GGA $+U$ methods (Fig. 4). As already highlighted in Blanchard et al. (2014), the effect of the Hubbard $\mathrm{U}$ correction is mostly visible on the $\mathrm{OH}$ bending and stretching modes. The $\mathrm{OH}$ bending frequencies increase while the $\mathrm{OH}$ stretching frequencies decrease, consistently with lengthening of the O-H bond. The pDOS and in particular the iron contribution is calculated using a $8 \times 4 \times 12 q$-points grid obtained through a Fourier (trigonometric) interpolation of the force constants (see Méheut et al., 2007, for details). We observe a general good agreement between the calculated and measured iron pDOS (Fig. 2a). In detail, small differences can be noted between the average measured pDOS and the calculated ones. These differences are of the same order of magnitude as the differences between the pDOS computed with GGA and $\mathrm{GGA}+U$, and are distributed all along the energy range, which suggests that they are not related to any specific vibrational modes. However, these small divergences lead to a significant difference in the calculated iron force constants that are equal to 233 $\mathrm{N} / \mathrm{m}$ and $247 \mathrm{~N} / \mathrm{m}$ using GGA and GGA $+U$, respectively. The force constant is calculated from the pDOS $g$ by using equation (5). The integral in the second moment of $g$ explains why the $\mathrm{OH}$ vibration modes with their high energies contribute a little to the iron force constant while the corresponding pDOS signal is almost negligible (Fig. 2). The difference between the DFT ( $233 \mathrm{~N} / \mathrm{m}$ for GGA, $247 \mathrm{~N} / \mathrm{m}$ for GGA+ $U$ ) 
and NRIXS $(268 \pm 8 \mathrm{~N} / \mathrm{m})$ force constants is already present before the $\mathrm{OH}$ vibration modes. Calculations show that the pDOS should be exactly zero over a certain energy range between the lattice modes and the $\mathrm{OH}$ bending modes (Fig. 2b), which is not the case for the NRIXS measurements and contributes to the overestimation of the iron force constant. This is likely due to the position of the baseline that should be slightly higher. The variability of the calculated ${ }^{57} \mathrm{Fe} /{ }^{54} \mathrm{Fe} \beta$ factor is shown in Fig. 5, and the corresponding temperature dependences are reported in Tables 1 and 5. Its variations follow variations in the iron force constant (Eq. 4). GGA and GGA+U results differ by $\sim 8 \%$ and it is not possible from the analysis of the vibrational properties to identify which computational method gives the best description of goethite. This difference should thus give an idea of the uncertainty intrinsic of DFT. These theoretical values are lower than the NRIXS-derived $\beta$ factor but higher than the $\beta$ factor determined by Polyakov and Mineev (2000) from the Mössbauer measurements done by de Grave and Vanderberghe (1986). Therefore with the new NRIXS data reduction, the discrepancy between the various analytical approaches is reduced but remains significant.

A general scaling factor reflecting the systematic underestimation of vibrational frequencies by the GGA functional is sometimes applied (e.g. Schauble 2011) or a mineral-dependent scaling factor is taken, assuming an accurate preliminary assignment of the vibrational modes (e.g. Blanchard et al. 2009). Here the theoretical $\beta$ factors were obtained by fixing the cell parameters to the experimental values and relaxing only the atomic positions. Following this procedure, we found that the interatomic bond lengths and therefore the vibrational frequencies are improved with respect to the fully optimized structure (i.e. relaxation of the cell parameters and atomic positions). No further frequency correction is needed. The iron 
$\beta$ factors of goethite calculated here are equal to $10.2 \%$ or $11.0 \%$ at $22^{\circ} \mathrm{C}$, using either GGA or GGA $+U$ methods. These values compare well with $10.5 \%$, which is the $\beta$ factor obtained from the fully relaxed structure and a frequency scale factor of 1.04 (quantified by taking the best linear-fit of the theoretical versus experimental frequencies). The same approach was applied to hematite, by keeping fixed the cell parameters of the rhombohedral primitive cell to the experimental values $(\mathrm{a}=5.427$ $\AA$ A $\alpha=55.28^{\circ}, R \overline{3} c$ space group, Finger and Hazen, 1980). Unlike goethite, the addition of the Hubbard $U$ clearly improves the atomic positions, interatomic distances and vibrational frequencies of hematite. Therefore, only GGA $+U$ results are retained and it is found that the new $\mathrm{GGA}+U$ iron $\beta$ factor is undistinguishable from the $\beta$ factor previously published in Blanchard et al. (2009) where a frequency scale factor of 1.083 was used. In a similar way, we checked for pyrite that the iron $\beta$ factor obtained with the experimental cell parameters (Brostigen and Kjekshus, 1969), i.e. $13.1 \%$ at $22^{\circ} \mathrm{C}$, is close, within the expected uncertainty, to the value calculated in Blanchard et al. (2009), i.e. $13.6 \%$. However we would like to emphasize that fixing the cell parameters to the experimental values do not dispense with checking that the calculated frequencies are in good agreement with the measured values.

\subsubsection{Oxygen $\beta$ factor of goethite and hematite}

Beside iron $\beta$ factors, first-principles calculations provide the ${ }^{18} \mathrm{O} /{ }^{16} \mathrm{O} \beta$ factor of goethite as a function of temperature (Fig. 6 and Table 6). For goethite, GGA and $\mathrm{GGA}+U$ results differ by $\sim 4 \%$. In the ideal goethite structure, half of the oxygen atoms are hydroxylated and the others are not. Calculations show that these two oxygen populations can be distinguished isotopically. At thermodynamic equilibrium, 
heavier isotopes will concentrate preferentially in hydroxylated sites. The oxygen isotope fractionation of goethite corresponds then to the average of all oxygen atoms

of the system. Similar calculations were also performed on hematite, using the same model as that previously used by Blanchard et al. (2009). As explained in section 3.2.1, only GGA $+U$ results are considered. With $\sim 62 \%$ at $25{ }^{\circ} \mathrm{C}$, the oxygen $\beta$ factor of hematite is found to be very close to the one of goethite, but with a slightly more linear temperature dependence (Fig. 6).

\section{DISCUSSION}

\subsection{Iron $\beta$ factor of goethite: intercomparison of the different methods}

In principle, DFT, NRIXS and Mössbauer spectroscopy should lead to statistically undistinguishable iron $\beta$ factors. In the case of hematite, an excellent agreement is found between DFT-derived ${ }^{57} \mathrm{Fe} /{ }^{54} \mathrm{Fe} \beta$ factor (i.e. $10.9 \%$ at $22{ }^{\circ} \mathrm{C}$, Blanchard et al. 2009) and NRIXS-derived ${ }^{57} \mathrm{Fe} /{ }^{54} \mathrm{Fe} \beta$ factor (i.e. $11.3 \pm 0.4 \%$ at 22 ${ }^{\circ} \mathrm{C}$, Dauphas et al. 2012). In the case of pyrite, the apparent discrepancy between DFT and Mössbauer results that was reported in Blanchard et al. (2009) and in Polyakov and Soultanov (2011), could be resolved by using a better constrained temperature dependence of the Mössbauer spectra (Blanchard et al. 2012). The first NRIXS-based estimation has recently confirmed our pyrite iron $\beta$ factor (Polyakov et al. 2013). In light of these previous studies, it is essential to investigate the origin of the scattering of the goethite iron $\beta$ factors obtained from the three analytical techniques.

The first obvious difference between goethite and hematite is the presence of hydrogen atoms, and it is well known that the accurate description of hydrogen bonding using DFT remains a concern. However, it is important to note that the 
lengths of the $\mathrm{Fe}-\mathrm{O}$ and $\mathrm{Fe}-\mathrm{OH}$ bonds are well described (Table 4) and that all vibrational frequencies below $700 \mathrm{~cm}^{-1}$ (i.e. excluding $\mathrm{OH}$ bending and stretching modes) compare well with the experimental values (Fig. 4). These vibrational modes are the main ones that contribute to the iron $\beta$ factor (Fig. 2c). The main difference between GGA, GGA $+U$ and NRIXS comes from the high-energy end of the lattice modes $\left(65-90 \mathrm{meV}\right.$ or $\left.525-725 \mathrm{~cm}^{-1}\right)$ and the fact that the NRIXS pDOS does not go down to zero between the lattice modes and $\mathrm{OH}$ bending modes (Fig. 2).

The nature and quality of the samples may also have an impact on iron isotope composition. On one hand, a ${ }^{57} \mathrm{Fe}$-rich sample with particle sizes of $\sim 20 \mathrm{~nm}$ was synthesized for the NRIXS measurements, and on the other hand, Mössbauer spectroscopy was done on natural sample from the Harz mountains, well-crystallized with particle size of $\sim 1 \mu \mathrm{m}$ (de Grave and Vandenberghe, 1986). Some kind of internal disorder is however commonly observed in goethite, using e.g. differential thermal analysis, infrared or magnetic measurements (Cornell and Schwertmann, 2003). This internal disorder may correspond to crystal defects and/or iron vacant sites that are compensated for by extra, non-stoichiometric protons. All this amounts to introducing distortions with respect to the ideal crystal structure. In "real" goethite crystals, there will be a larger variation in the length of Fe-O bonds, which will lead to a larger variation of the local iron $\beta$ factors (i.e. $\beta$ factors associated with each iron atom). In a similar but simpler way, the ideal goethite structure displays already two oxygen populations with specific isotopic signatures and the bulk oxygen $\beta$ factor corresponds to the average of these two local $\beta$ factors (Fig. 6). The prediction of the iron $\beta$ factor of a goethite crystal containing a certain amount of defects would require the accurate characterization of the sample at the molecular scale, which is beyond the scope of the present paper. It is noteworthy that the presence of defective sites is not 
necessarily expressed in the overall isotopic composition because compensation of local $\beta$ factors may occur. For instance, Blanchard et al. (2010) investigated the isotopic properties of hematite with iron vacant sites compensated by protons. The local iron $\beta$ factors display variations over a significant range $\left(1.1 \%\right.$ at $\left.0{ }^{\circ} \mathrm{C}\right)$, but extreme values compensate each other, resulting for the model investigated, in a negligible effect of these cationic vacancies on the iron isotope composition of hematite. Similarly, we built a $2 \times 1 \times 2$ supercell of goethite containing one iron vacancy compensated by three protons. The overall ${ }^{57} \mathrm{Fe} /{ }^{54} \mathrm{Fe}$ ffactor is almost unchanged (11.99\%o instead of $11.94 \%$ at $0{ }^{\circ} \mathrm{C}$ using GGA), even if the local $\beta$ factors display values ranging from $11.22 \%$ to $13.61 \%$ at $0{ }^{\circ} \mathrm{C}$ (the highest value, i.e. $13.61 \%$, corresponds to an iron atom surrounded by two vacancies because of the periodic repetition of the simulation cell).

Iron force constant and $\beta$ factor can also be affected by surface sites, the contribution of which should depend on the size of the crystals. Unlike for defects in bulk, the molecular relaxation in vicinity of the surfaces will more likely give rise to a specific isotopic signature that will affect the overall isotopic composition. Beard et al. (2010) and Frierdich et al. (2014) investigated the isotopic exchange between aqueous $\mathrm{Fe}(\mathrm{II})$ and goethite, using two sizes of goethite. Their results demonstrate that the equilibrium isotopic properties of nano-scale minerals may be distinct from micron-scale or larger minerals. They found that iron surface sites are enriched in heavy isotopes compared to bulk goethite. This fractionation is consistent with the fact that the NRIXS-derived $\beta$ factor (for a nano-scale sample) is higher than the Mössbauer-derived $\beta$ factor (for a micron-scale sample). However the difference observed in $\beta$ factors (Fig. 5) is large compared to the difference in equilibrium 
fractionation measured by Frierdich et al. (2014) for various particle sizes. Rustad and Dixon (2009) examined iron isotope fractionation between hematite and aqueous iron, and found almost no difference between bulk and surface $\beta$ factors. This conclusion applies to the (012) hematite surface with molecularly and dissociatively adsorbed water, using DFT calculations and the embedded cluster approach. Only few experimental and theoretical data exist on the topic. More studies are needed with other mineral surfaces and more structurally-complex surfaces.

\subsection{Isotopic fractionations between minerals (afactors)}

The experimental iron isotope fractionation factors between goethite, hematite and pyrite in condition of thermodynamic equilibrium can be determined by combining the measurements from Skulan et al. (2002), Welch et al. (2003), Syverson et al. (2013) and Frierdich et al. (2014) (Table 7). Keeping in mind that these mineralmineral isotopic fractionations do not represent direct measurements and involve approximations like temperature extrapolations, we can compare them with the equilibrium fractionation factors estimated from NRIXS, Mössbauer or DFT (Fig. 7). The range of iron $\beta$ factors obtained for goethite (Fig. 5) leads to a significant spread of iron $\theta$ factors for pyrite-goethite and hematite-goethite (Fig. 7). DFT efactor is in good agreement with the experimental pyrite-hematite value (0.62\%o compared to $\Delta^{57} \mathrm{Fe}=0.44 \pm 1.0 \%$ at $350{ }^{\circ} \mathrm{C}$ ). For pyrite-goethite, DFT ofactors (GGA and $\mathrm{GGA}+U$ ) are within the error bar of the experimental data. For hematite-goethite, DFT curves are 1-2 \%o lower than the experimental points at $98{ }^{\circ} \mathrm{C}$. The Mössbauerderived $\beta$ factor of goethite (Polyakov and Mineev 2000) seems to be in better agreement with experimental points, while NRIXS data fall in the lowest part of the 
range (i.e., little iron isotopic fractionation between goethite and hematite). The same conclusions could also be reached looking at the isotopic fractionation between aqueous Fe(II) and goethite ( Frierdich et al. 2014). However this would require to combine the present mineral $\beta$ factors with a $\mathrm{Fe}(\mathrm{II})_{\mathrm{aq}} \beta$ factor obtained from a different technique (for instance, the DFT values from Rustad et al., 2010, currently considered as the most reliable, and based on an aperiodic model, B3LYP exchange-correlation functional and localized basis sets). This practice should be considered with caution and the combination of $\beta$ factors determined by a single methodology is always preferable.

It often happens that the iron $\beta$ factors derived from Mössbauer are slightly different and lower than the ones derived from NRIXS, but usually when the ofactors are determined the agreement between these two methods and with the experimental data is satisfactory. This is shown, for instance, for the isotopic fractionation between molten silicate, FeS and metal (Dauphas et al., 2014).

For the oxygen isotopes, DFT results $(\mathrm{GGA}$ and $\mathrm{GGA}+U)$ indicate a small equilibrium fractionation between hematite and goethite (between -3.1 and $+0.8 \%$ o over the whole temperature range, Fig. 8). These theoretical estimations are consistent with the study of Yapp (1990), which suggests, from synthesis experiments conducted in the temperature range $25-120{ }^{\circ} \mathrm{C}$, that goethite and hematite are isotopically indistinguishable at equilibrium. Several experimental studies also investigated oxygen isotope fractionation in hematite-water and goethite-water systems (e.g. Bao and Koch, 1999; Yapp, 2007). The hematite-goethite fractionation curve that can be derived from Bao and Koch (1999) shows a similar temperature-dependence as our GGA results but is slightly more positive (Fig. 8). In this study, experiments of goethite synthesis were performed at a $\mathrm{pH}$ higher than 14. However Yapp's results 
(2007) suggest that, in addition to temperature, $\mathrm{pH}$ can affect the measured oxygen isotope fractionation between goethite and water. He found for goethite synthesized at low $\mathrm{pH}(\sim 1$ to 2$)$ a curve that differs significantly from the ones obtained at high $\mathrm{pH}$ (>14). Using this low-pH curve for goethite-water from Yapp (2007) and the hematite-water oxygen fractionation from Bao and Koch (1999), the hematite-goethite fractionation curve falls in the range predicted by DFT methods but with an stronger temperature-dependence (Fig. 8). According to Yapp (2007), data measured for goethite crystallized at low $\mathrm{pH}$ may approach isotopic equilibrium values. These data are therefore the ones that must be compared preferentially with the DFT results. In conclusion, theoretical estimations for oxygen isotopes are consistent with experimental measurements, even if the exact temperature-dependence remains uncertain.

Our data display a significant discrepancy with the results of the semi-empirical approach of Zheng (1991, 1998), i.e. the modified increment method where the equilibrium oxygen isotope fractionation factors of oxides are assessed with respect to a reference mineral (quartz) by considering the bond-type in the crystal structure (e.g., bond strength, effect of mass on isotopic substitution). Blanchard et al. (2010) already reported a discrepancy for the oxygen isotope fractionation between hematite and corundum, suggesting that the modified increment method cannot be used to reliably predict isotopic fractionation factors.

\section{ACKNOWLEDGMENTS}

L. Paulatto is acknowledged for his technical support to the computational work. This work was performed using HPC resources from GENCI-IDRIS (Grant 2014-i2014041519). This work has been supported by the French National Research 
Agency (ANR, projects 11-JS56-001 "CrIMin" and 2011JS56 00401 "FrIHIDDA"), grants from NSF (EAR 1144429) and NASA (NNX12AH60G). Use of the Advanced Photon Source, an Office of Science User Facility operated for the U.S. Department of Energy (DOE) Office of Science by Argonne National Laboratory, was supported by the U.S. DOE under Contract No. DE-AC02-06CH11357. 


\section{REFERENCES}

Bao H. and Koch P.L. (1999) Oxygen isotope fractionation in ferric oxide-water systems: Low temperature synthesis. Geochim. Cosmochim. Acta 63, 599-613.

Baroni S., de Gironcoli S., Dal Corso A. and Giannozzi P. (2001) Phonons and related crystal properties from density-functional perturbation theory. Rev. Mod. Phys. 73, 515-561.

Beard B. L., Handler R. M., Scherer M. M., Wu L., Czaja A. D., Heimann A. and Johnson C. M. (2010) Iron isotope fractionation between aqueous ferrous iron and goethite. Earth Planet. Sci. Lett. 295, 241-250.

Blanchard M., Lazzeri M., Mauri F. and Balan E. (2008) First-principles calculation of the infrared spectrum of hematite. Am. Mineral. 93, 1019-1027.

Blanchard M., Poitrasson F., Méheut M., Lazzeri M., Mauri F. and Balan E. (2009) Iron isotope fractionation between pyrite $\left(\mathrm{FeS}_{2}\right)$, hematite $\left(\mathrm{Fe}_{2} \mathrm{O}_{3}\right)$ and siderite $\left(\mathrm{FeCO}_{3}\right)$ : a first-principles density-functional theory study. Geochim. Cosmochim. Acta 73, 6565-6578.

Blanchard M., Morin G., Lazzeri M. and Balan E. (2010) First-principles study of the structural and isotopic properties of Al- and $\mathrm{OH}-$ bearing hematite. Geochim. Cosmochim. Acta 74, 3948-3962.

Blanchard M., Poitrasson F., Méheut M., Lazzeri M., Mauri F. and Balan E. (2012) Comment on "New data on equilibrium iron isotope fractionation among sulfides: Constraints on mechanisms of sulfide formation in hydrothermal and igneous systems" by V.B. Polyakov and D.M. Soultanov. Geochim. Cosmochim. Acta, 87, 356-359.

Blanchard M., Balan E., Giura P., Béneut K., Yi H., Morin G., Pinilla C., Lazzeri M. and Floris A. (2014) Infrared spectroscopic properties of goethite: anharmonic 
broadening, long-range electrostatic effects and Al substitution. Phys. Chem. Minerals, 41, 289-302.

Brostigen G. and Kjekshus A. (1969) Redetermined crystal structure of $\mathrm{FeS}_{2}$ (pyrite). Acta Chem. Scand., 23, 2186-2188.

Cambier P. (1986) Infrared study of goethites of varying crystallinity and particle size: I. Interpretation of $\mathrm{OH}$ and lattice frequencies. Clay Minerals 21, 191-200.

Cococcioni M. and de Gironcoli S. (2005) Linear response approach to the calculation of the effective interaction parameters in the LDA+U method. Phys. Rev. B 71, 035105.

Cornell R. M. and Schwertmann U. (2003) The iron oxides: structure, properties, reactions, occurrences and uses. 2nd ed., Wiley-VCH, pp. 664

Dauphas N., Roskosz M., Alp E. E., Golden D. C., Sio C. K., Tissot F. L. H., Hu M. Y., Zhao J., Gao L. and Morris R. V. (2012) A general moment NRIXS approach to the determination of equilibrium Fe isotopic fractionation factors: Application to goethite and jarosite. Geochim. Cosmochim. Acta 94, 254-275

Dauphas N., Roskosz M., Alp E. E., Neuville D., Hu M., Sio C. K., Tissot F. L. H., Zhao J., Tissandier L., Medard E. and Cordier C. (2014) Magma redox and structural controls on iron isotope variations in Earth's mantle and crust. Earth Planet. Sci. Lett., 398, 127-140

de Faria D. L. A. and Lopes F. N. (2007) Heated goethite and natural hematite: Can Raman spectroscopy be used to differentiate them? Vibrational spectroscopy $\mathbf{4 5}$, $117-121$

de Grave E. and Vandenberghe R. E. (1986) ${ }^{57} \mathrm{Fe}$ Mössbauer effect study of wellcrystalized goethite $(\alpha \mathrm{FeOOH})$. Hyperfine Interactions 28, 643-646.

Eiler J. M., Bergquist B., Bourg I., Cartigny P., Farquhar J., Gagnon A., Guo W., 
Halevy I., Hofmann A., Larson T. E., Levin N., Schauble E. A. and Stolper D. (2014) Frontiers of stable isotope geoscience. Chem. Geol. 373, 119-143.

Finger L. W. and Hazen R. M. (1980) Crystal structure and isothermal compression of $\mathrm{Fe}_{2} \mathrm{O}_{3}, \mathrm{Cr}_{2} \mathrm{O}_{3}$, and $\mathrm{V}_{2} \mathrm{O}_{3}$ to 50 kbars. J. Appl. Phys. 51, 5362-5367.

Floris A., de Gironcoli S., Gross E. K. U. and Cococcioni M. (2011) Vibrational properties of $\mathrm{MnO}$ and $\mathrm{NiO}$ from $\mathrm{DFT}+\mathrm{U}-$ based Density Functional Perturbation Theory, Phys. Rev. B 84, 161102(R).

Frierdich A. J., Beard B. L., Reddy T. R., Scherer M. M. and Johnson C. M. (2014) Iron isotope fractionation between aqueous $\mathrm{Fe}(\mathrm{II})$ and goethite revisited: New insights based on a multi-direction approach to equilibrium and isotopic exchange rate modification. Geochim. Cosmochim. Acta. 139, 383-398.

Giannozzi P., Baroni S., Bonini N., Calandra M., Car R., Cavazzoni C., Ceresoli D., Chiarotti G. L., Cococcioni M., Dabo I., Dal Corso A., de Gironcoli S., Fabris S., Fratesi G., Gebauer R., Gerstmann U., Gougoussis C., Kokalj A., Lazzeri M., Martin-Samos L., Marzari N., Mauri F., Mazzarello R., Paolini S., Pasquarello A., Paulatto L., Sbraccia C., Scandolo S., Sclauzero G., Seitsonen A. P., Smogunov A., Umari P. and Wentzcovitch R. M. (2009) Quantum ESPRESSO: a modular and open-source software project for quantum simulations of materials. J. Phys.: Conden.s Matter 21, 395502.

Golden D. C., Ming D. W., Morris R. V. and Gra $\square$ T. G. (2008) Hydrothermal synthesis of hematite spherules and jarosite: Implications for diagenesis and hematite spherule formation in sulfate outcrops at Meridiani Planum, Mars. Am. Mineral. 93, 1201-1214.

Hu M., Sturhahn Y. W., Toellner T. S., Mannheim P. D., Brown D. E., Zhao J. and Alp E. E. (2003) Measuring velocity of sound with nuclear resonant inelastic x- 
ray scattering, Phys. Rev. B 67, 094304.

Hu M. Y., Toellner T. S., Dauphas N., Alp E. E. and Zhao J. (2013) Moments in nuclear resonant inelastic x-ray scattering and their applications. Phys. Rev. B 87, 064301

Johnson C. M., Beard B. L. and Albarède F. (2004) Geochemistry of non-traditional isotopes. Rev. Mineral. Geochem., vol. 55. Mineralogical Society of America, Geochemical Society. 454 p.

Johnson D. W. and Spence J. C. H. (1974) Determination of the single-scattering probability distribution from plural-scattering data. J. Phys. D: Applied Physics 7, $771-780$

Kohn V. G. and Chumakov A. I. (2000) DOS: Evaluation of phonon density of states from nuclear resonant inelastic absorption. Hyperfine Interactions 125, 205-221.

Kulik H. J., Cococcioni M., Scherlis D. A. and Marzari N. (2006) Density functional theory in transition-metal chemistry: a self-consistent Hubbard $U$ approach. Phys. Rev. Lett. 97 ,103001.

Méheut M., Lazzeri M., Balan E. and Mauri F. (2007) Equilibrium isotopic fractionation in the kaolinite, quartz, water system: Prediction from firstprinciples density-functional theory. Geochim. Cosmochim. Acta 71, 3170-3181.

Monkhorst H. J. and Pack J. D. (1976) Special points for Brillouin-zone integrations. Phys. Rev. B 13, 5188-5192.

Otte K., Pentcheva R., Schmahl W. W. and Rustad J. R. (2009) Pressure-induced structural and electronic transitions in $\mathrm{FeOOH}$ from first- principles. Phys. Rev. B 80, 205116.

Perdew J. P., Burke K. and Ernzerhof M. (1996) Generalized gradient approximation made simple. Phys. Rev. Lett. 77, 3865-3868. 
Polyakov V. B. and Mineev S. D. (2000) The use of Mössbauer spectroscopy in stable isotope geochemistry. Geochim. Cosmochim. Acta 64, 849-865.

Polyakov V. B., Mineev S. D., Clayton R. N., Hu G. and Mineev K. S. (2005) Determination of tin equilibrium isotope fractionation factors from synchroton radiation experiments. Geochim. Cosmochim. Acta 69, 5531-5536.

Polyakov V. B., Clayton R. N., Horita J. and Mineev S. D. (2007) Equilibrium iron isotope fractionation factors of minerals: Reevaluation from the data of nuclear inelastic resonant X-ray scattering and Mössbauer spectroscopy. Geochim. Cosmochim. Acta 71, 3833-3846.

Polyakov V. B. and Soultanov D. M. (2011) New data on equilibrium iron isotope fractionation among sulfides: Constraints on mechanisms of sulfide formation in hydrothermal and igneous systems. Geochim. Cosmochim. Acta 75, 1957-1974.

Polyakov V. B., Osadchii E. G., Chareev D. A., Chumakov A. I. and Sergeev I. A. (2013) Fe $\beta$ factors for sulfides from NRIXS synchrotron experiments. Mineral. Mag., 77, 1985.

Rustad J.R. and Dixon D.A. (2009) Prediction of iron-isotope fractionation between hematite $\left(\alpha \mathrm{Fe}_{2} \mathrm{O}_{3}\right)$ and ferric and ferrous iron in aqueous solution from Density Functional Theory. J. Phys. Chem. A, 113, 12249-12255.

Rustad J.R., Casey W.H., Yin Q-Z., Bylaska E.J., Felmy A.R., Bogatko S.A., Jackson V.E. and Dixon D.A. (2010) Isotopic fractionation of $\mathrm{Mg}^{2+}(\mathrm{aq}), \mathrm{Ca}^{2+}(\mathrm{aq})$, and $\mathrm{Fe}^{2+}(\mathrm{aq})$ with carbonate minerals. Geochim. Cosmochim. Acta 74, 6301-6323.

Schauble E. A. (2011) First-principles estimates of equilibrium magnesium isotope fractionation in silicate, oxide, carbonate and hexaaquamagnesium(2+) crystals. Geochim. Cosmochim. Acta 75, 844-869.

Seto M., Yoda Y., Kikuta S., Zhang X. W. and Ando M. (1995) Observation of 
nuclear resonant scattering accompanied by phonon excitation using synchrotron radiation. Phys. Rev. Lett. 74, 3828-3831.

Skulan J. L., Beard B. L. and Johnson C. M. (2002) Kinetic and equilibrium Fe isotope fractionation between aqueous $\mathrm{Fe}(\mathrm{III})$ and hematite. Geochim. Cosmochim. Acta 66, 2995-3015.

Sturhahn W., Toellner T. S., Alp E. E., Zhang X., Ando M., Yoda Y., Kikuta S., Seto M., Kimball C. W. and Dabrowski B. (1995) Phonon density of states measured by inelastic nuclear resonant scattering. Phys. Rev. Lett. 74, 3832-3835.

Sturhahn W. (2000) CONUSS and PHOENIX: Evaluation of nuclear resonant scattering data. Hyperfine Interactions 125, 149-172.

Sturhahn W. and Jackson J. M. (2007) Geophysical applications of nuclear resonant scattering, in Ohtani, E., ed., Advances in High-Pressure Mineralogy: GSA Special Paper 421, 157-174.

Syverson D. D., Borrock D. M. and Seyfried Jr. W. E. (2013) Experimental determination of equilibrium $\mathrm{Fe}$ isotopic fractionation between pyrite and dissolved Fe under hydrothermal conditions. Geochim. Cosmochim. Acta 122, 170-183.

Valley J. W. and Cole D. R. (2001) Stable isotope geochemistry. Rev. Mineral. Geochem., vol. 43. Mineralogical Society of America, Geochemical Society. 662 p.

Welch S. A., Beard B. L., Johnson C. M. and Braterman P. S. (2003) Kinetic and equilibrium $\mathrm{Fe}$ isotope fractionation between aqueous $\mathrm{Fe}(\mathrm{II})$ and $\mathrm{Fe}(\mathrm{III})$. Geochim. Cosmochim. Acta 67, 4231-4250.

Yang H., Lu R., Downs R. T., Costin G. (2006) Goethite, $\alpha \mathrm{FeO}(\mathrm{OH})$, from singlecrystal data. Acta Crystallographica E62, i250-i252. 
Yapp C. J. (1990) Oxygen isotopes in iron (III) oxides, 1. Mineral-water fractionation factors. Chem. Geol. 85, 329-335.

Yapp C. J. (2007) Oxygen isotopes in synthetic goethite and a model for the apparent $\mathrm{pH}$ dependence of goethite-water ${ }^{18} \mathrm{O} /{ }^{16} \mathrm{O}$ fractionation. Geochim. Cosmochim. Acta 71, 1115-1129.

Zheng Y. F. (1991) Calculation of oxygen isotope fractionation in metal oxides. Geochim. Cosmochim. Acta 55, 2299-2307.

Zheng Y. F. (1998) Oxygen isotope fractionation between hydroxide minerals and water. Phys. Chem. Minerals 25, 213-221. 


\section{TABLES}

Table 1. Goethite properties derived from NRIXS, based on the scattering spectrum, $S(\mathrm{E})$, or the projected partial phonon density of states, $g(\mathrm{E})$.

\begin{tabular}{|c|c|c|c|c|c|c|c|c|c|c|c|c|}
\hline \multirow[b]{2}{*}{ Parameters from $\mathrm{S}$} & \multicolumn{3}{|c|}{ Goethite 1} & \multicolumn{3}{|c|}{ Goethite 2} & \multicolumn{3}{|c|}{ Goethite 3} & \multicolumn{3}{|c|}{ Mean for Goethite } \\
\hline & & & & & & & & & & & & \\
\hline Temperature from detailed balance $(\mathrm{K})$ & 287 & & & 302 & & & 296 & & & 295 & & \\
\hline Lamb-Mössbauer factor from $\mathrm{S}$ & 0.7741 & \pm & 0.0026 & 0.7548 & \pm & 0.0020 & 0.7604 & \pm & 0.0020 & 0.7614 & \pm & 0.0012 \\
\hline Mean square displacement $<\mathrm{z}^{2}>$ from $\mathrm{S}\left(\AA^{2}\right)$ & 0.00481 & \pm & 0.00006 & 0.00528 & \pm & 0.00005 & 0.00514 & \pm & 0.00004 & 0.00511 & \pm & 0.00003 \\
\hline Internal energy/atom from $\mathrm{S}(\mathrm{meV})$ & 29.00 & \pm & 0.73 & 29.17 & \pm & 0.67 & 28.95 & \pm & 0.67 & 29.04 & \pm & 0.40 \\
\hline Kinetic energy/atom from $\mathrm{S}(\mathrm{meV})$ & 14.50 & \pm & 0.37 & 14.58 & \pm & 0.34 & 14.48 & \pm & 0.34 & 14.52 & \pm & 0.20 \\
\hline Force constant from $\mathrm{S}(\mathrm{N} / \mathrm{m})$ & 277 & \pm & 15 & 264 & \pm & 13 & 267 & \pm & 13 & 268 & \pm & 8 \\
\hline (without truncation/baseline subtraction) & $(319$ & \pm & 17) & $(250$ & \pm & 16) & $(260$ & \pm & 14) & & & \\
\hline \multicolumn{13}{|l|}{${ }^{56} \mathrm{Fe} /{ }^{54} \mathrm{Fe} \beta$ coefficients from $\mathrm{S}$} \\
\hline \multicolumn{13}{|l|}{$1000 \ln \beta=\mathrm{A}_{1} / \mathrm{T}^{2}+\mathrm{A}_{2} / \mathrm{T}^{4}+\mathrm{A}_{3} / \mathrm{T}^{6}(\mathrm{~T}$ in $\mathrm{K})$} \\
\hline $\mathrm{A}_{1}$ & $7.898 \mathrm{E}+05$ & \pm & $4.384 \mathrm{E}+04$ & $7.537 \mathrm{E}+05$ & \pm & $3.755 \mathrm{E}+04$ & $7.605 \mathrm{E}+05$ & \pm & $3.724 \mathrm{E}+04$ & $7.659 E+05$ & \pm & $2.264 E+04$ \\
\hline $\mathrm{A}_{2}$ & $-5.074 \mathrm{E}+09$ & \pm & $6.634 \mathrm{E}+08$ & $-5.382 \mathrm{E}+09$ & \pm & $7.678 \mathrm{E}+08$ & $-5.474 \mathrm{E}+09$ & \pm & $6.729 \mathrm{E}+08$ & $-5.301 E+09$ & \pm & $4.024 E+08$ \\
\hline $\mathrm{A}_{3}$ & $7.516 \mathrm{E}+13$ & \pm & $1.866 \mathrm{E}+13$ & $1.154 \mathrm{E}+14$ & \pm & $3.225 \mathrm{E}+13$ & $1.111 \mathrm{E}+14$ & \pm & $2.430 \mathrm{E}+13$ & $9.318 E+13$ & \pm & $1.345 E+13$ \\
\hline \multicolumn{13}{|l|}{$1000 \ln \beta=\mathrm{B}_{1}<\mathrm{F}>/ \mathrm{T}^{2}-\mathrm{B}_{2}<\mathrm{F}>^{2} / \mathrm{T}^{4}(\mathrm{~T}$ in $\mathrm{K})$} \\
\hline $\mathrm{B}_{1}$ & 2853 & & & 2853 & & & 2853 & & & 2853 & & \\
\hline $\mathrm{B}_{2}$ & 55630 & & & 59269 & & & 60154 & & & 58351 & & \\
\hline \multicolumn{13}{|l|}{ Parameters from $\mathrm{g}$} \\
\hline Lamb-Mössbauer factor from g & 0.7740 & & & 0.7546 & & & 0.7602 & & & 0.7629 & & \\
\hline Mean square displacement $\left\langle\mathrm{z}^{2}\right\rangle$ from $g\left(\AA^{2}\right)$ & 0.00481 & & & 0.00528 & & & 0.00515 & & & 0.00508 & & \\
\hline $\mathrm{d}<\mathrm{z}^{2}>/ \mathrm{dT}\left(\AA^{2} / \mathrm{K}\right)$ & $1.45 \mathrm{E}-05$ & & & $1.60 \mathrm{E}-05$ & & & $1.56 \mathrm{E}-05$ & & & $1.54 E-05$ & & \\
\hline Critical temperature $(\mathrm{K})$ & 1295 & & & 1170 & & & 1203 & & & 1222 & & \\
\hline Resilience (N/m) & 95 & & & 86 & & & 88 & & & 90 & & \\
\hline Internal energy/atom from $\mathrm{g}(\mathrm{meV})$ & 29.76 & & & 29.92 & & & 29.70 & & & 29.80 & & \\
\hline Kinetic energy/atom from $\mathrm{g}(\mathrm{meV})$ & 14.88 & & & 14.96 & & & 14.85 & & & 14.90 & & \\
\hline Vibrational entropy (kb/atom) & 1.00 & & & 1.05 & & & 1.03 & & & 1.03 & & \\
\hline Helmholtz free energy (meV) & 3.89 & & & 2.60 & & & 2.86 & & & 3.12 & & \\
\hline Vibrational specific heat (kb/atom) & 0.87 & & & 0.89 & & & 0.88 & & & 0.88 & & \\
\hline Lamb-Mössbauer factor at $\mathrm{T}=0$ & 0.92 & & & 0.92 & & & 0.92 & & & 0.92 & & \\
\hline Kinetic energy/atom at $\mathrm{T}=0(\mathrm{meV})$ & 7.91 & & & 7.68 & & & 7.69 & & & 7.76 & & \\
\hline
\end{tabular}


Force constant from g (N/m)

$1000 \ln \beta=\mathrm{A}_{1} / \mathrm{T}^{2}+\mathrm{A}_{2} / \mathrm{T}^{4}+\mathrm{A}_{3} / \mathrm{T}^{6}(\mathrm{~T}$ in $\mathrm{K})$

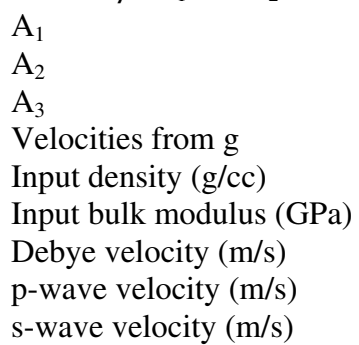

Input bulk modulus (GPa)

Debye velocity $(\mathrm{m} / \mathrm{s})$

p-wave velocity $(\mathrm{m} / \mathrm{s})$

$\mathrm{s}$-wave velocity $(\mathrm{m} / \mathrm{s})$

$7.884 \mathrm{E}+05$

$-5.060 \mathrm{E}+09$

$7.814 \mathrm{E}+13$

$7.490 \mathrm{E}+05$

$-5.333 \mathrm{E}+09$

$7.580 \mathrm{E}+05$

$-5.442 \mathrm{E}+09$

$7.652 E+05$

$1.158 \mathrm{E}+14$

$1.128 \mathrm{E}+14$

$-5.278 E+09$

$1.023 E+14$

$3934 \pm 43$

$6480 \pm 29$

3526

$6395 \pm 26$

$3409 \pm 37$

108.5

$3899 \pm 46$

$6456 \pm 3$

$3493 \pm 44$

0.302

0.293

4.27

108.5

$3874 \pm 25$

$6439 \pm 17$

$3470 \pm 23$

Poisson ratio 
Table 2. Hydronium-jarosite and potassium-jarosite properties derived from NRIXS, based on the scattering spectrum, S(E), or the projected partial phonon density of states, $\mathrm{g}(\mathrm{E})$.

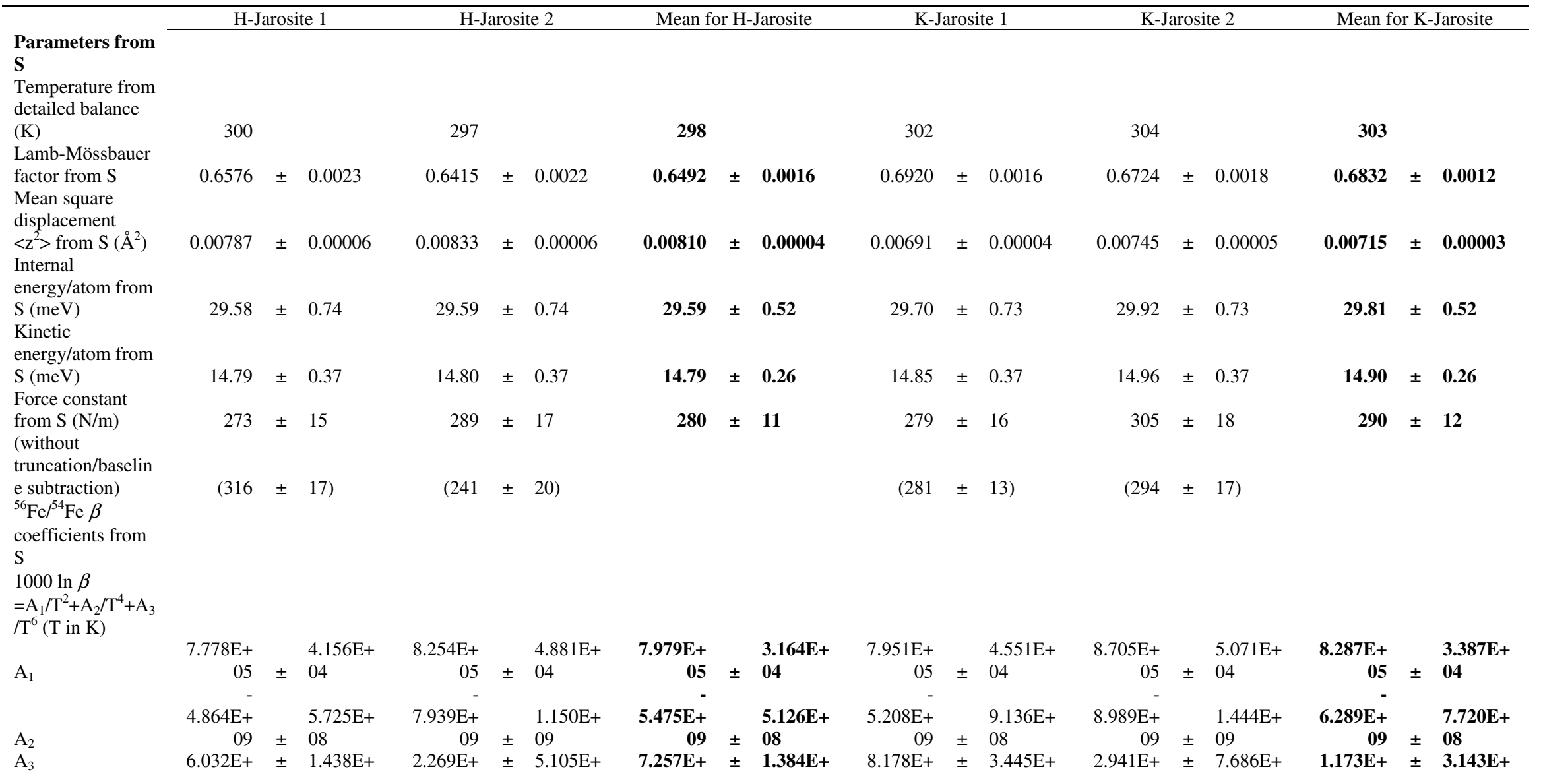


$1000 \ln \beta$
$=\mathrm{B}_{1}<\mathrm{F}>/ \mathrm{T}^{2}$

$\mathrm{B}_{2}<\mathrm{F}>>^{2} / \mathrm{T}^{4}$ ( $\mathrm{T}$ in

$\mathrm{K})$

$\mathrm{B}_{1}$

$\mathrm{B}_{2}$

2853

\section{Parameters from}

Lamb-Mössbauer

factor from $g$

Mean square

displacement

$<\mathrm{z}^{2}>$ from g $\left(\AA^{2}\right) \quad 0.00789$

2.47E-05

Critical

temperature (K)

760

Resilience (N/m)

energy/atom from

0.6815

energy/atom from

$\mathrm{g}(\mathrm{meV})$

entropy (kb/atom)

specific heat

(kb/atom)

Kinetic

energy/atom at

$\mathrm{T}=0(\mathrm{meV})$

Force constant

from $\mathrm{g}(\mathrm{N} / \mathrm{m})$ 


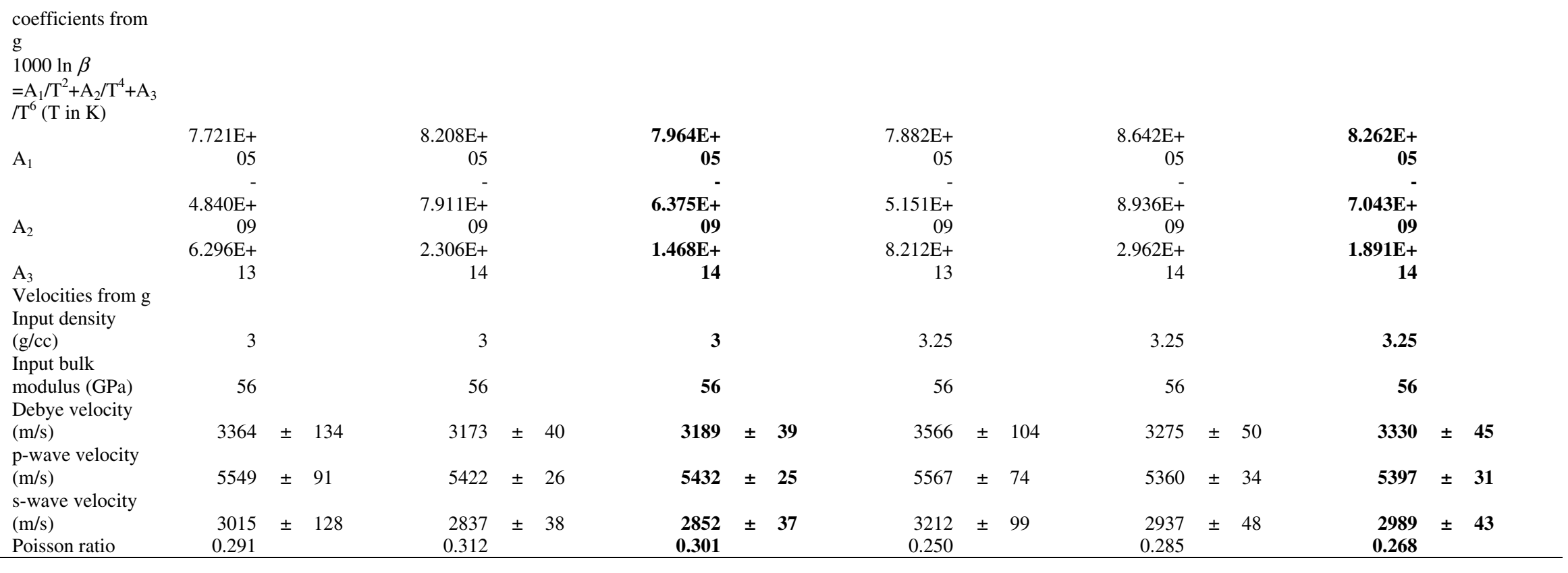


Table 3. Theoretical and experimental atomic coordinates $[ \pm(x, y, 3 / 4)$, $\pm(1 / 2+\mathrm{x}, 1 / 2+\mathrm{y}, 1 / 4)]$ of goethite. Values in brackets give the differences with respect to the experimental values.

\begin{tabular}{lcccccccc}
\hline & $\mathrm{xFe}$ & $\mathrm{yFe}$ & $\mathrm{xH}$ & $\mathrm{yH}$ & $\mathrm{xO}$ & $\mathrm{yO}$ & $\mathrm{xOh}$ & $\mathrm{yOh}$ \\
\hline GGA & 0.0503 & 0.8523 & 0.4041 & 0.0855 & 0.6978 & 0.2001 & 0.1989 & 0.0528 \\
& $(0.001)$ & $(-0.001)$ & $(0.026)$ & $(0.004)$ & $(-0.008)$ & $(0.001)$ & $(0.000)$ & $(0.000)$ \\
GGA $+U$ & 0.0603 & 0.8559 & 0.4011 & 0.0940 & 0.6798 & 0.1946 & 0.1959 & 0.0570 \\
& $(0.011)$ & $(0.002)$ & $(0.023)$ & $(0.012)$ & $(-0.026)$ & $(-0.005)$ & $(-0.003)$ & $(0.004)$ \\
Exp.* & 0.0489 & 0.8537 & 0.3781 & 0.0817 & 0.7057 & 0.1991 & 0.1987 & 0.0530 \\
\hline
\end{tabular}

*Yang et al. (2006)

Table 4. Theoretical and experimental interatomic distances $(\AA)$. Values in brackets give the differences with respect to the experimental values.

\begin{tabular}{llll}
\hline & $\mathrm{Fe}-\mathrm{O}$ & $\mathrm{Fe}-\mathrm{Oh}$ & $\mathrm{O}-\mathrm{H}$ \\
\hline GGA & $1.8963(-0.037)$ & $2.1091(0.010)$ & $0.9975(0.125)$ \\
& $1.9725(0.017)$ & $2.1167(0.011)$ & \\
GGA $U$ & $1.9484(0.015)$ & $2.0958(-0.004)$ & $1.0130(0.140)$ \\
& $1.9889(0.033)$ & $2.1018(-0.004)$ & \\
Exp. $^{*}$ & 1.9332 & 2.0994 & 0.8729 \\
& 1.9560 & 2.1059 & \\
\hline
\end{tabular}

*Yang et al. (2006)

Table 5. Fits of the calculated $10^{3} \ln \beta$ based on the function $a x+b x^{2}+c x^{3}$, with $x=$ $10^{6} / T^{2}(T$ on $\mathrm{K})$ for ${ }^{57} \mathrm{Fe} /{ }^{54} \mathrm{Fe}$ isotope fractionation in goethite.

\begin{tabular}{lccc}
\hline & $\mathrm{a}$ & $\mathrm{b}$ & $\mathrm{c}$ \\
\hline $\mathrm{GGA}$ & $9.384 \times 10^{-1}$ & $-4.7789 \times 10^{-3}$ & $4.9888 \times 10^{-5}$ \\
GGA $+U$ & $10.248 \times 10^{-1}$ & $-5.8539 \times 10^{-3}$ & $6.8122 \times 10^{-5}$ \\
\hline
\end{tabular}


Table 6. Fits of the calculated $10^{3} \ln \beta$ based on the function $a x+b x^{2}+c x^{3}$, with $x=$ $10^{6} / T^{2}\left(T\right.$ on $\mathrm{K}$ ) for ${ }^{18} \mathrm{O} /{ }^{16} \mathrm{O}$ isotope fractionation in goethite and hematite.

\begin{tabular}{llccc}
\hline & & $\mathrm{a}$ & $\mathrm{b}$ & $\mathrm{c}$ \\
\hline Goethite O total & GGA & 6.9558 & $-1.9730 \times 10^{-1}$ & $5.7833 \times 10^{-3}$ \\
Goethite O total & GGA+U & 7.1664 & $-1.8753 \times 10^{-1}$ & $5.2786 \times 10^{-3}$ \\
Goethite O & GGA & 5.2325 & $-4.2571 \times 10^{-2}$ & $4.3992 \times 10^{-4}$ \\
Goethite O & GGA+U & 5.5402 & $-4.9704>10^{-2}$ & $5.8375>10^{-4}$ \\
Goethite Oh & GGA & 8.6748 & $-3.5227>10^{-1}$ & $1.1134>10^{-2}$ \\
Goethite Oh & GGA+U & 8.7932 & $-3.2570 \times 10^{-1}$ & $9.9755 \times 10^{-3}$ \\
Hematite O & GGA+U & 6.0030 & $-5.1020 \times 10^{-2}$ & $5.1786 \times 10^{-4}$ \\
\hline
\end{tabular}

Table 7. Mineral-mineral iron isotope fractionations determined from experimental measurements. The extrapolation to higher temperature is made assuming a linear dependence as a function of $10^{6} / T^{2}$ and a fractionation equal to zero at infinite temperature. $\Delta^{56} \mathrm{Fe}$ shown here are subsequently converted in $\Delta^{57} \mathrm{Fe}$ for comparison in Fig. 6.

\begin{tabular}{|c|c|c|c|}
\hline $\begin{array}{c}\text { Pyrite-Fe(II) })_{\mathbf{a q}} \\
\text { Syverson et al. (2013) }\end{array}$ & $\begin{array}{c}\mathbf{F e}(\mathbf{I I})_{\mathbf{a q}} \text {-Goethite } \\
\text { Frierdich et al. (2014) }\end{array}$ & & Pyrite-Goethite \\
\hline $\begin{array}{c}0.99 \pm 0.3 \% \\
\text { at } 350{ }^{\circ} \mathrm{C}\end{array}$ & $\begin{array}{c}-0.23 \pm 0.1 \% \circ \\
-0.27 \pm 0.1 \%{ }^{*} \\
\text { extrapol. to } 350{ }^{\circ} \mathrm{C}\end{array}$ & & $\begin{array}{c}0.76 \pm 0.3 \% \circ \\
0.72 \pm 0.3 \% \circ \\
\text { at } 350{ }^{\circ} \mathrm{C}\end{array}$ \\
\hline $\begin{array}{l}\text { Hematite-Fe(III) })_{\mathbf{a q}} \\
\text { Skulan et al. (2002) }\end{array}$ & $\begin{array}{c}\mathbf{F e}(\mathbf{I I I})_{\mathbf{a q}}-\mathbf{F e}(\mathbf{I I})_{\mathbf{a q}} \\
\text { Welch et al. (2003) }\end{array}$ & $\begin{array}{c}\mathbf{F e}(\mathbf{I I})_{\mathbf{a q}}-\mathbf{G o e t h i t e} \\
\text { Frierdich et al. (2014) }\end{array}$ & Hematite-Goethite \\
\hline $\begin{array}{c}0.1 \pm 0.2 \% o \\
\text { at } 98{ }^{\circ} \mathrm{C}\end{array}$ & $\begin{array}{c}1.87 \pm 0.2 \% 0 \\
\text { extrapol. to } 98{ }^{\circ} \mathrm{C}\end{array}$ & $\begin{array}{c}-0.66 \pm 0.1 \% \circ \\
-0.77 \pm 0.1 \%{ }^{*} \\
\text { extrapol. to } 98{ }^{\circ} \mathrm{C}\end{array}$ & $\begin{array}{c}1.31 \pm 0.3 \% \circ \\
1.2 \pm 0.3 \% \circ \\
\text { at } 98{ }^{\circ} \mathrm{C}\end{array}$ \\
\hline $\begin{array}{c}\text { Pyrite-Fe(II) })_{\mathrm{aq}} \\
\text { Syverson et al. (2013) }\end{array}$ & $\begin{array}{c}\mathbf{F e}(\mathbf{I I})_{\mathrm{aq}}-\mathbf{F e}(\mathbf{I I I})_{\mathrm{aq}} \\
\text { Welch et al. }(2003)\end{array}$ & $\begin{array}{l}\mathbf{F e}(\mathbf{I I I})_{\mathbf{a q}} \text {-Hematite } \\
\text { Skulan et al. (2002) }\end{array}$ & Pyrite-Hematite \\
\hline $\begin{array}{c}0.99 \pm 0.3 \% o \\
\text { at } 350{ }^{\circ} \mathrm{C}\end{array}$ & $\begin{array}{c}-0.66 \pm 0.2 \% \circ \\
\text { extrapol. to } 350{ }^{\circ} \mathrm{C} \\
\end{array}$ & $\begin{array}{c}-0.04 \pm 0.2 \% \circ \\
\text { extrapol. to } 350{ }^{\circ} \mathrm{C}\end{array}$ & $\begin{array}{c}0.29 \pm 0.4 \% o \\
\text { at } 350{ }^{\circ} \mathrm{C} \\
\end{array}$ \\
\hline
\end{tabular}

* smaller particles 


\section{Figure Captions}

Figure 1. Comparison between iron mean force constant determinations by NRIXS with or without baseline subtraction. The baseline is a linear interpolation between signal measured at the low- and high-energy ends of the NRIXS spectrum, where no phonon contributions are expected. Baseline subtraction yields force constant values that display better long-term reproducibility compared to no baseline subtraction (the different replicates were measured at during several beamline sessions spanning three years).

Figure 2. (a) Average measured (NRIXS) and calculated (GGA, GGA+U) phonon density of states (pDOS) of iron atoms in goethite. (b) The iron pDOS and total pDOS calculated with GGA are plotted along with the calculated (circles) and experimental (triangles) infrared and Raman frequencies (Cambier, 1986; de Faria and Lopes, 2007). This highlights the energy gap existing between lattice modes and $\mathrm{OH}$ bending modes. (c, d) The force constant is calculated from the pDOS by using the formula $\langle F\rangle=\frac{M}{\hbar^{2}} \int_{0}^{\lambda} g(E) E^{2} d E$, with the upper limit $\lambda=\infty$ (Eq. 5). The term $g(E) E^{2}$ is plotted in (c), while the force constant integral for different values of the integration upper-limit is plotted in (d).

Figure 3. Average phonon density of states of iron atoms in hydronium-jarosite and potassium-jarosite measured using NRIXS.

Figure 4. Calculated $(\mathrm{GGA}$ and $\mathrm{GGA}+U$ ) versus experimental infrared and Raman frequencies of goethite (Cambier, 1986; de Faria and Lopes, 2007). 
Figure 5. Temperature dependence of the iron $\beta$ factor of goethite.

Figure 6. Temperature dependence of the oxygen $\beta$ factor of goethite and hematite.

Figure 7. Temperature dependence of the iron $\theta$ factor between pyrite and goethite, and between hematite and goethite. The experimental points have not been measured directly and are estimated instead from several experiments, which are compiled in Table 7 (Skulan et al., 2002; Welch et al., 2003; Syverson et al., 2013; Frierdich et al., 2014). For Mössbauer, pyrite, hematite and goethite data are taken from Blanchard et al. (2012), Polyakov et al. (2007) and Polyakov and Mineev (2000), respectively. For GGA and GGA $+U$, pyrite and hematite data are from Blanchard et al. (2009) while goethite data correspond to this study. For NRIXS, hematite data are from Dauphas et al. (2012) and goethite data are from this study. No NRIXS iron $\beta$ factor is published yet for pyrite.

Figure 8. Temperature dependence of the oxygen offactor between hematite and goethite. For GGA and GGA $+U$, hematite data are from Blanchard et al. (2009) while goethite data are from this study. Results of the semi-empirical approach of Zheng (1991, 1998) are shown for comparison, as well as the following experimental data: Exp. 1 corresponds to data from Bao and Koch (1999) where goethite was synthesized at high $\mathrm{pH}(>14)$, and Exp. 2 combines the hematite-water isotopic fractionation factors from Bao and Koch (1999) with goethite-water data at low $\mathrm{pH}$ ( 1 to 2) from Yapp (2007). 


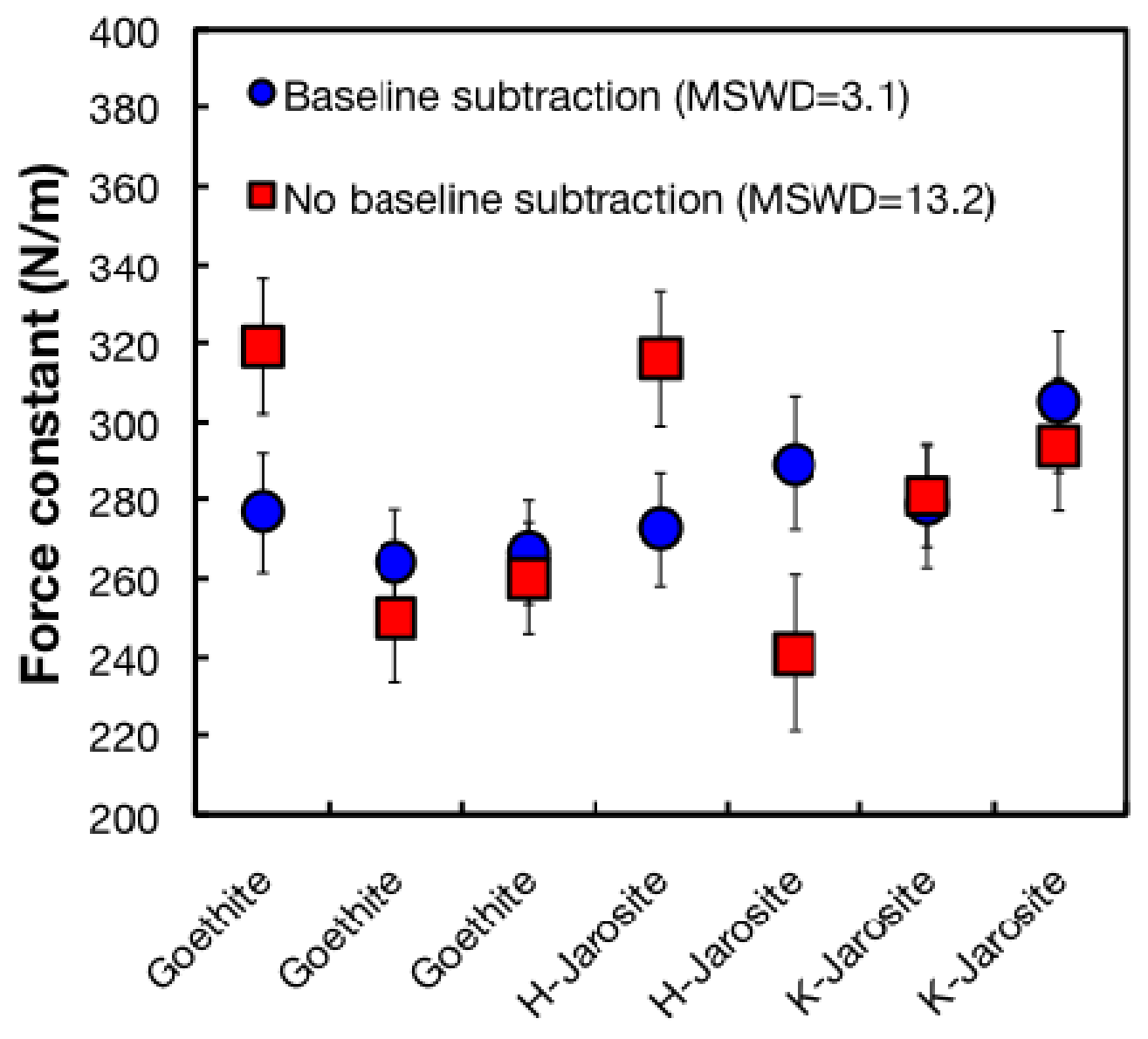

Figure 1. 

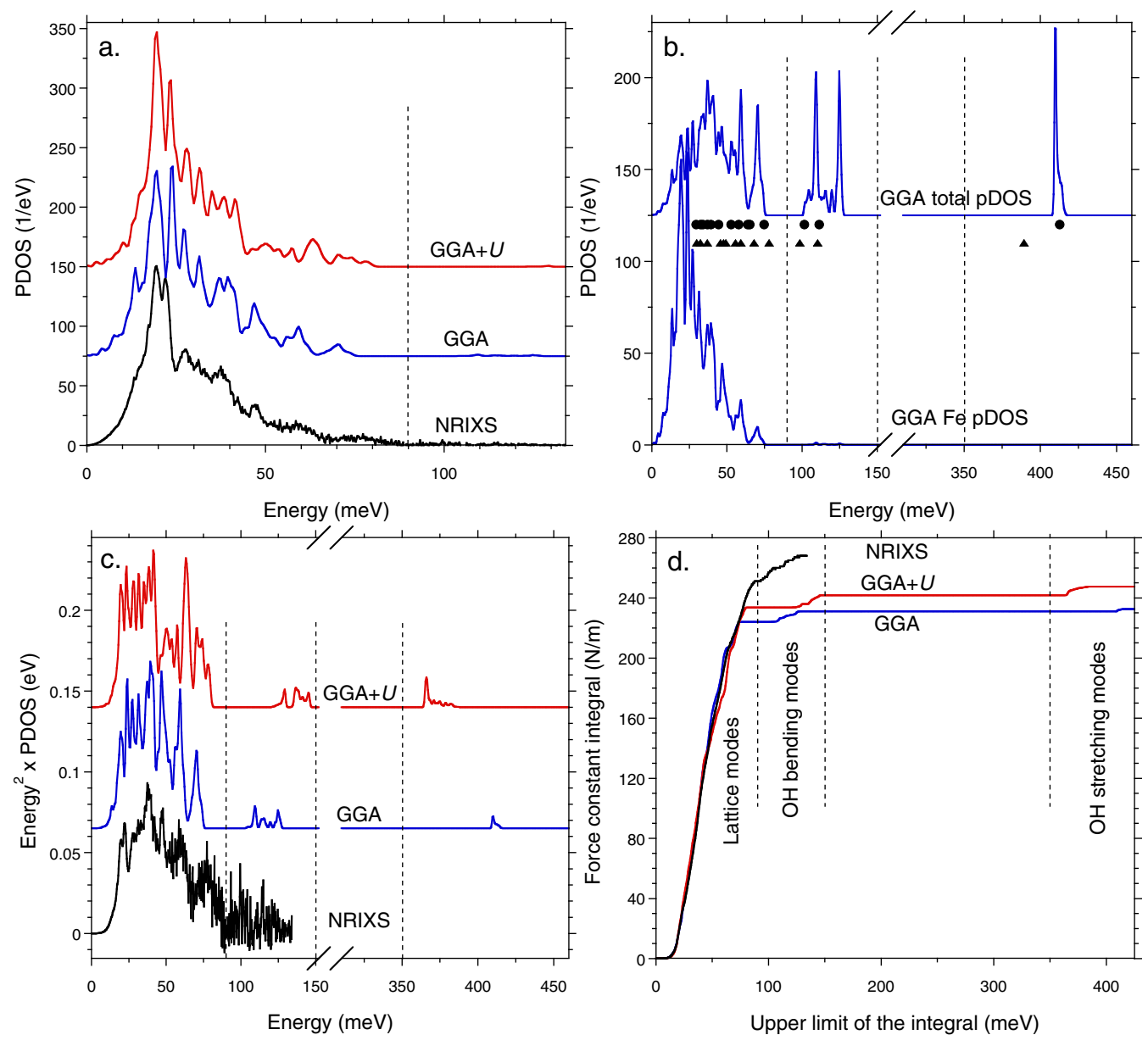

Figure 2.
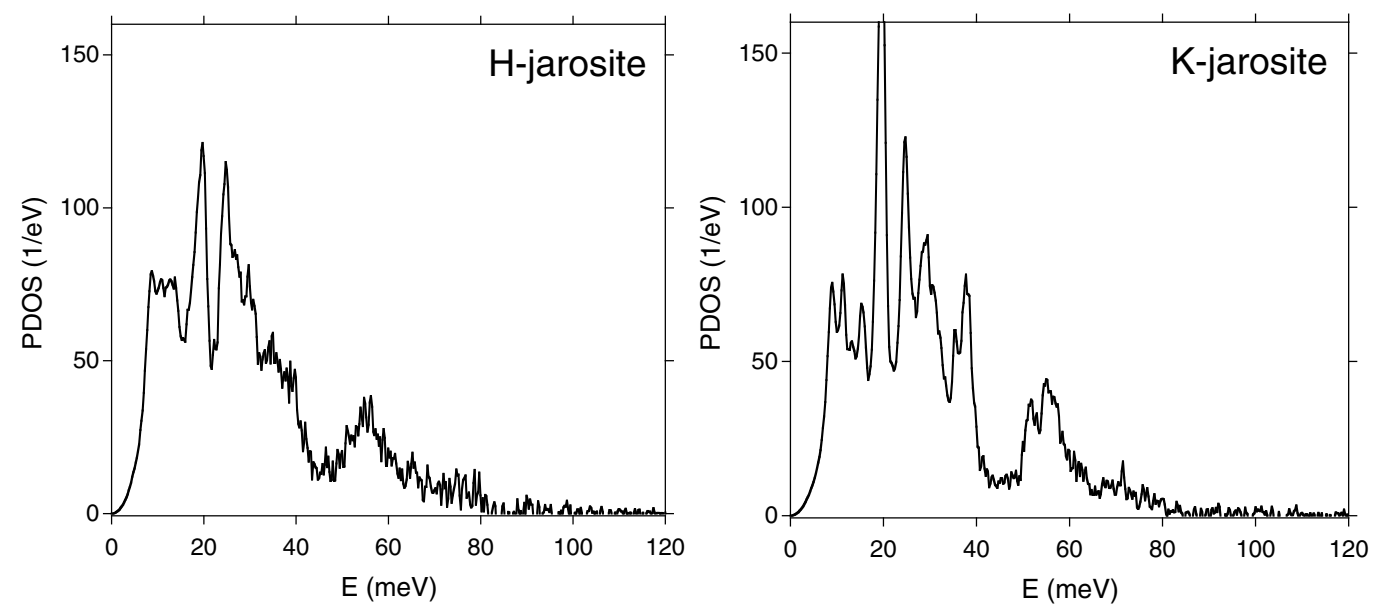

Figure 3. 


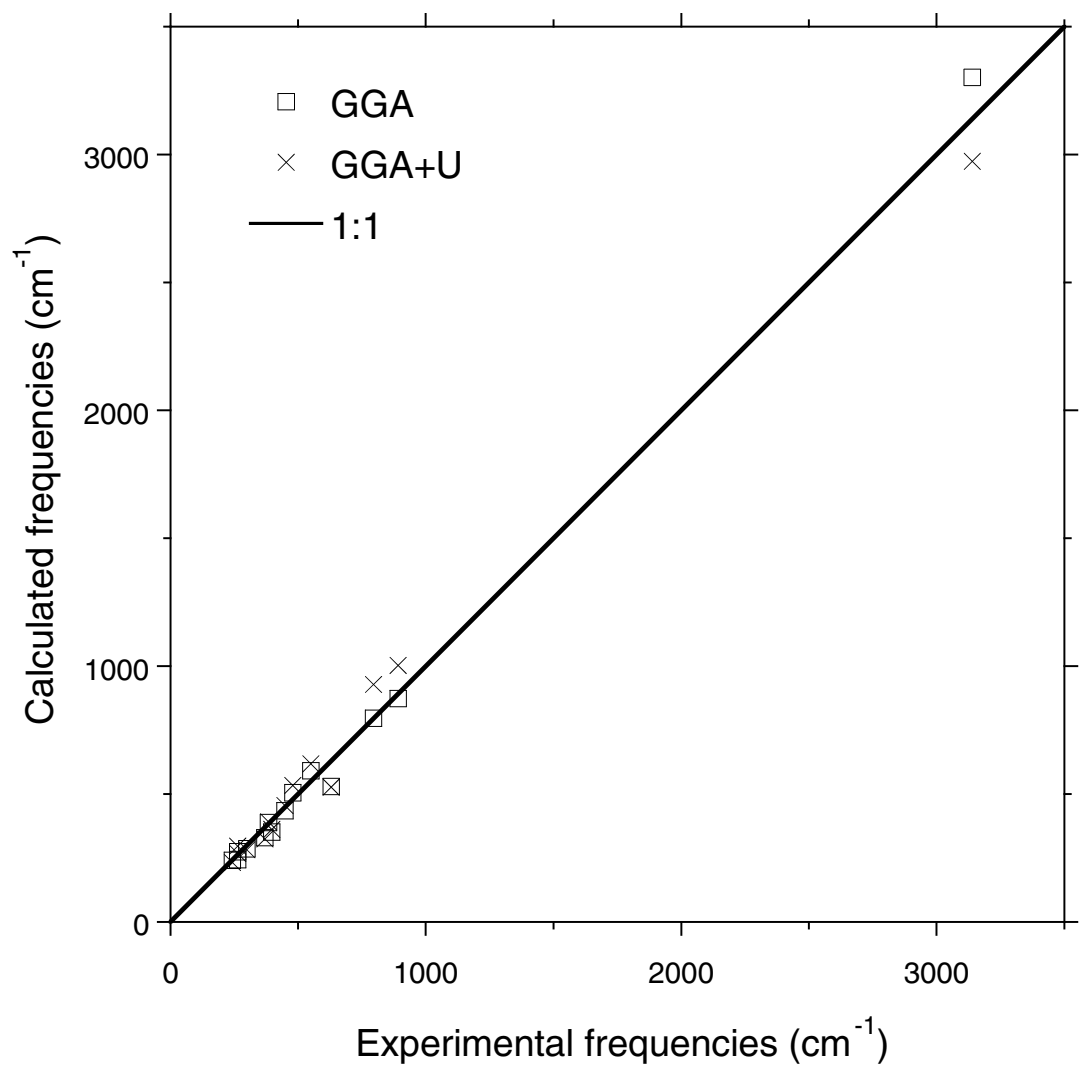

Figure 4. 


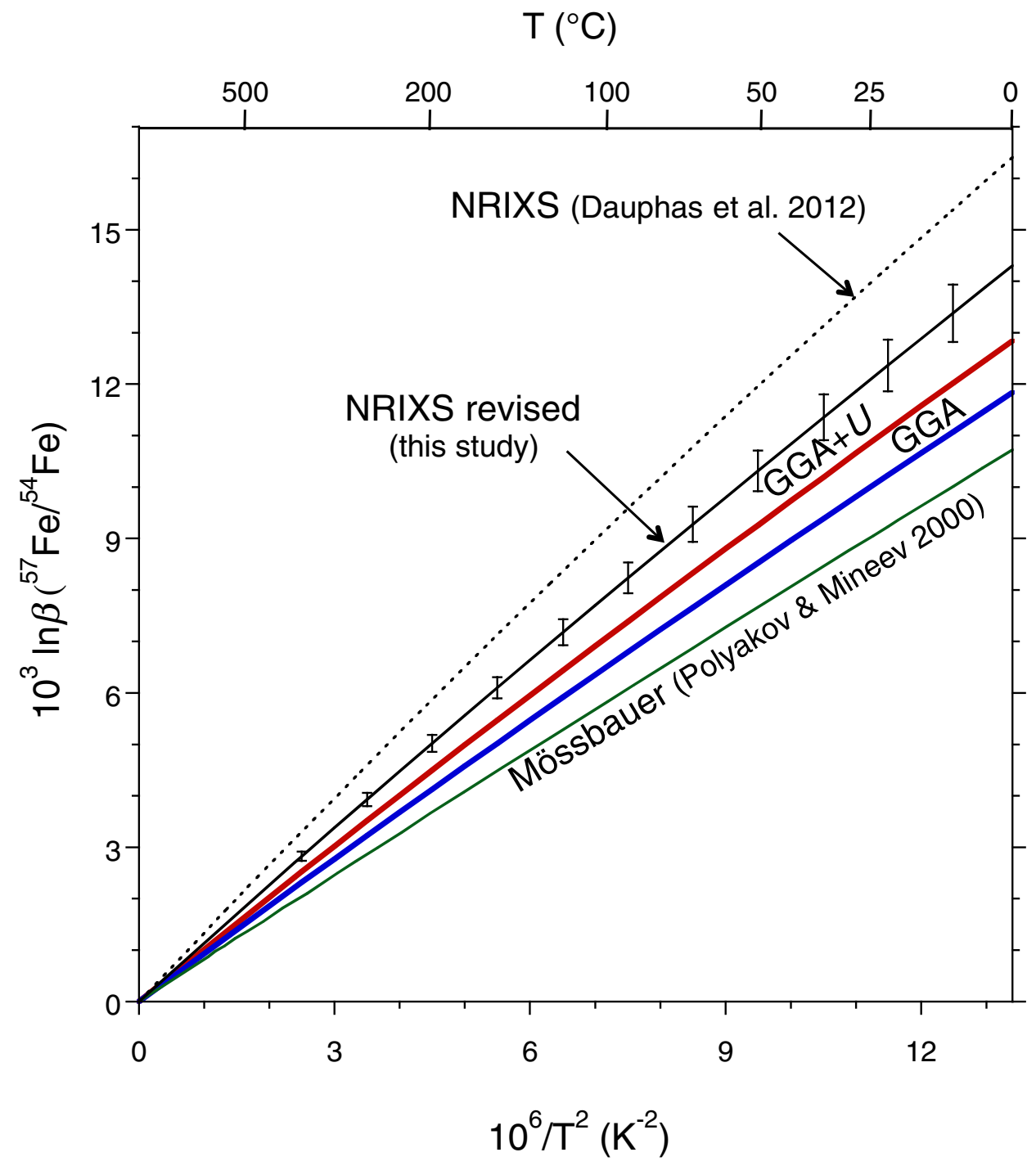

Figure 5. 

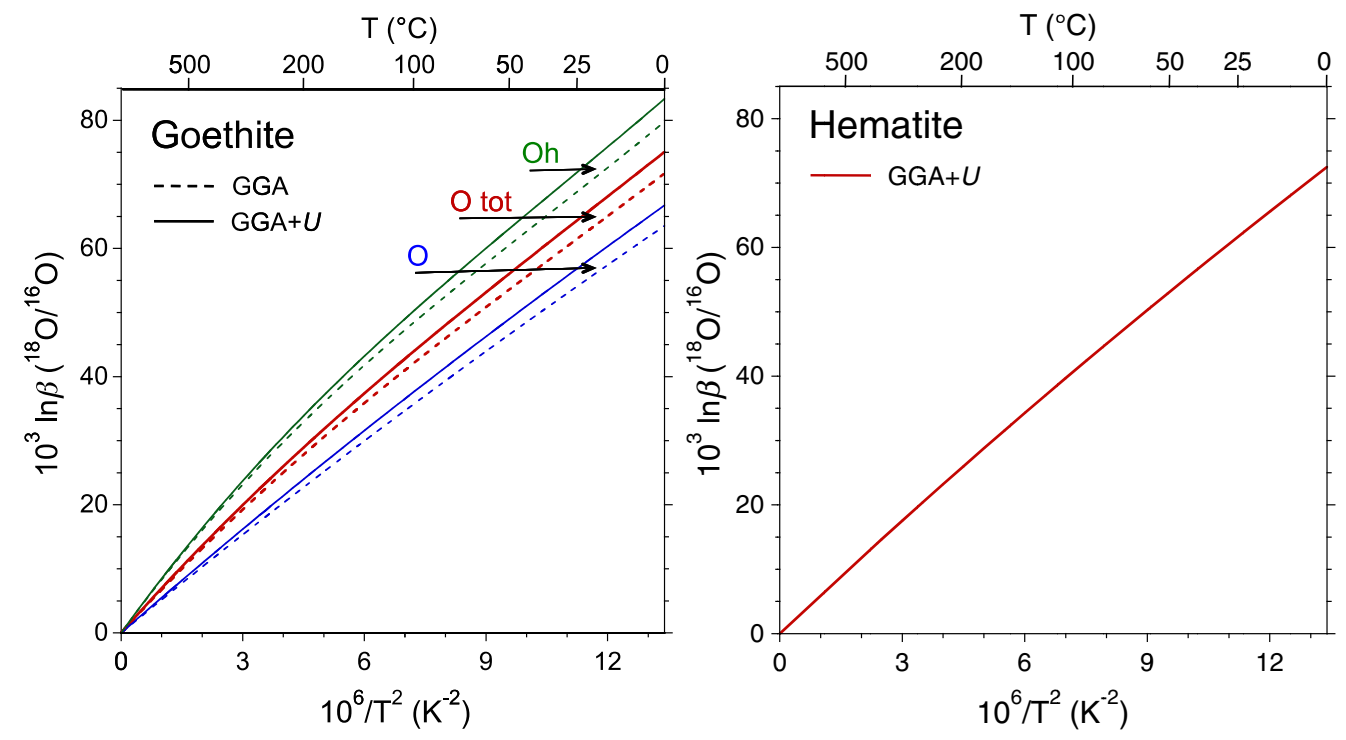

Figure 6.
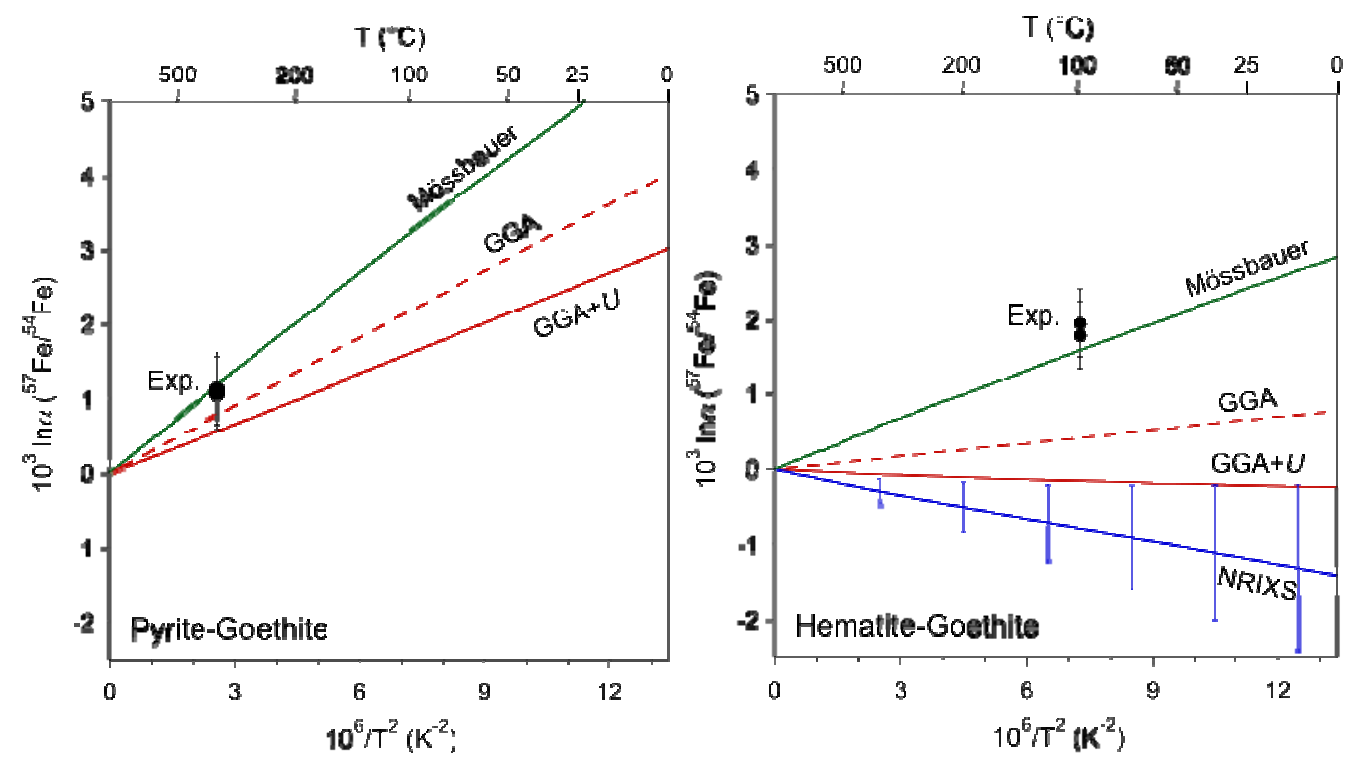

Figure 7. 


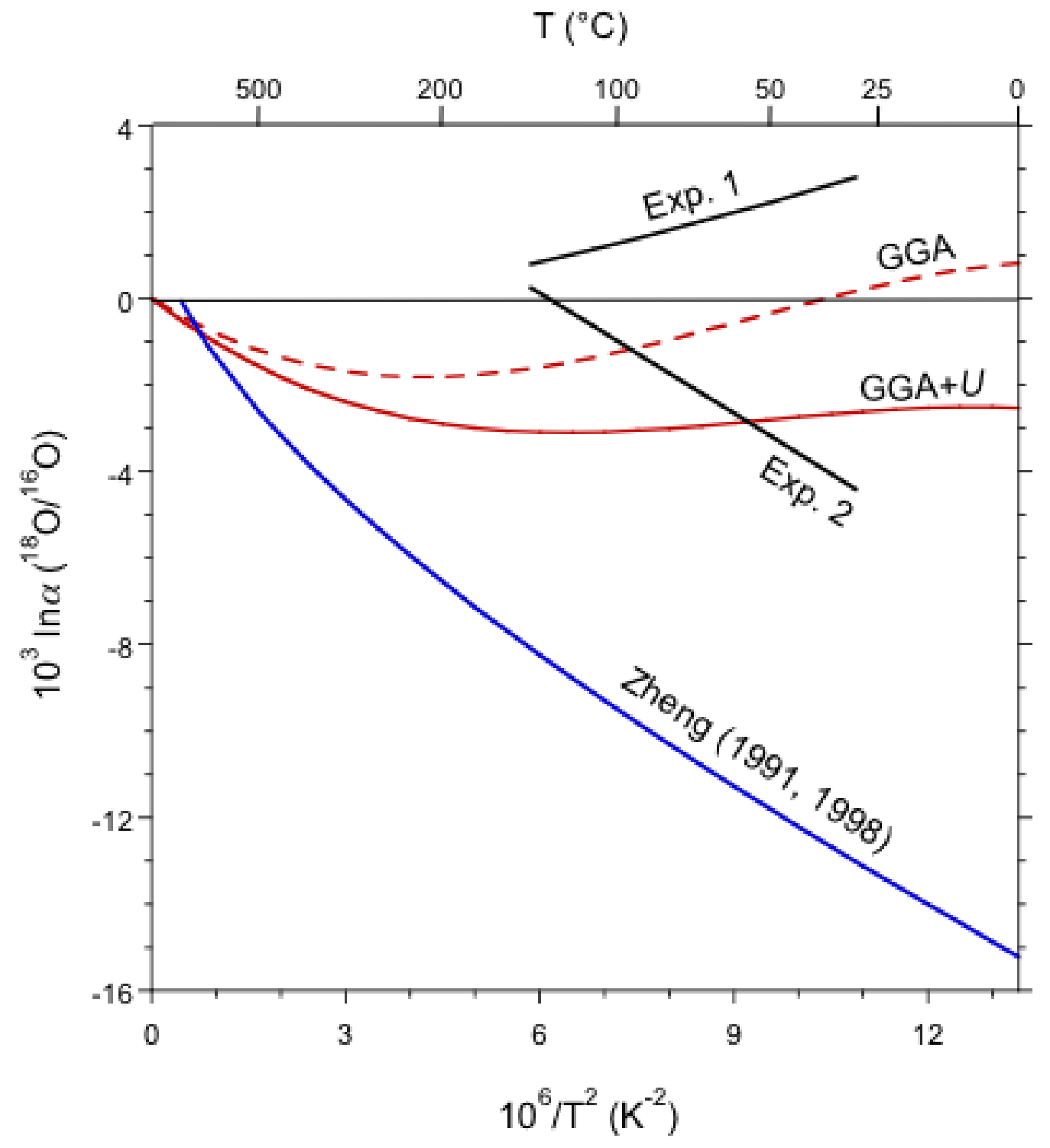

Figure 8. 